NBER WORKING PAPER SERIES

\title{
THE COGNITIVE EFFECTS OF MICRONUTRIENT DEFICIENCY: EVIDENCE FROM SALT IODIZATION IN THE UNITED STATES
}

\author{
James Feyrer \\ Dimitra Politi \\ David N. Weil \\ Working Paper 19233 \\ http://www.nber.org/papers/w19233 \\ NATIONAL BUREAU OF ECONOMIC RESEARCH \\ 1050 Massachusetts Avenue \\ Cambridge, MA 02138 \\ July 2013
}

We would like to thank Hoyt Bleakley, Kenneth Chay, Andrew Clausen, Joseph Ferrie, seminar participants at Tel Aviv University, Boston College, Brown University, Northwestern University, and conference participants at the NBER's Cohort Studies Meeting, AEA Meetings and SIRE Young Researchers' Forum for helpful comments. Desislava Byanova, Federico Droller, Bryce Millett Steinberg, and Young Min Kim provided excellent research assistance. The views expressed herein are those of the authors and do not necessarily reflect the views of the National Bureau of Economic Research.

NBER working papers are circulated for discussion and comment purposes. They have not been peerreviewed or been subject to the review by the NBER Board of Directors that accompanies official NBER publications.

(C) 2013 by James Feyrer, Dimitra Politi, and David N. Weil. All rights reserved. Short sections of text, not to exceed two paragraphs, may be quoted without explicit permission provided that full credit, including $(\subset$ notice, is given to the source. 
The Cognitive Effects of Micronutrient Deficiency: Evidence from Salt Iodization in the United States

James Feyrer, Dimitra Politi, and David N. Weil

NBER Working Paper No. 19233

July 2013

JEL No. I18,I28,J24,N32

\begin{abstract}
Iodine deficiency is the leading cause of preventable mental retardation in the world today. The condition, which was common in the developed world until the introduction of iodized salt in the 1920s, is connected to low iodine levels in the soil and water. We examine the impact of salt iodization on cognitive outcomes in the US by taking advantage of this natural geographic variation. Salt was iodized over a very short period of time beginning in 1924. We use military data collected during WWI and WWII to compare outcomes of cohorts born before and after iodization, in localities that were naturally poor and rich in iodine. We "find that for the one quarter of the population most deficient in iodine this intervention raised IQ by approximately one standard deviation. Our results can explain roughly one decade's worth of the upwardtrend in IQ in the US (the Flynn Effect). We also document a large increase in thyroid related deaths following the countrywide adoption of iodized salt, which affected mostly older individuals in localities with high prevalence of iodine deficiency.
\end{abstract}

James Feyrer

Department of Economics

Dartmouth College

6106 Rockefeller Hall

Hanover, NH 03755-3514

and NBER

james.feyrer@dartmouth.edu

Dimitra Politi

School of Economics

31 Buccleuch Place

Edinburgh

EH8 9JT

UK

dimitra.politi@ed.ac.uk
David N. Weil

Department of Economics

Box B

Brown University

Providence, RI 02912

and NBER

david_weil@brown.edu 


\section{Introduction}

Deficiencies in the consumption of micronutrients, the vitamins and minerals required in trace amounts for proper metabolic functioning, are a major contributor to poor health in developing countries. For example, in 2005, some 667 thousand deaths of children under five $(6.3 \%$ of all such deaths worldwide) were estimated to be attributable to vitamin A deficiency. The mortality burden of zinc deficiency was roughly two-thirds as large ${ }^{1}$. The World Health Organization estimates that that nearly 50 million people suffer some degree of mental impairment due to iodine deficiency, and that this is the leading cause of preventable mental retardation in the world. Anemia, the most important cause of which is inadequate intake of iron, affects 1.6 billion people around the globe ${ }^{2}$.

In developed countries, as recently as the first half of the twentieth century the toll of micronutrient deficiencies was also significant. This included rickets due to inadequate vitamin $\mathrm{D}$ in industrial cities; pellagra due to inadequate niacin consumption among populations dependent on maize; and iodine deficiency. A combination of dietary improvements and widespread food fortification has eliminated these problems.

Around the developing world, there are now in place numerous programs of micronutrient supplementation. Between 1999 and 2007, the fraction of children aged 6-59 months receiving full vitamin A supplementation in UNICEF-priority countries rose from $16 \%$ to $72 \%$. Since 2004, 46 countries have adopted zinc supplementation as part of their child health policies. In China, the fraction of salt iodized rose from 30\% to $96 \%$ between 1990 and 2000, and India banned the sale of non-iodized salt for human consumption in $2006^{3}$. In both Vietnam and the Philippines there are National Micronutrient Days, featuring education and distribution of supplements.

The 2008 Copenhagen Consensus ranked micronutrient supplementation for children

\footnotetext{
${ }^{1}$ By comparison, stunting, severe wasting, and intrauterine growth restriction, all primarily resulting from protein-energy malnutrition, were together responsible for $21 \%$ of deaths in this age group (Black, Allen, Bhutta, Caulfield, De Onis, Ezzati, Mathers and Rivera 2008).

${ }^{2}$ de Benoist, Mclean, Egli and Cogswell, eds (2008), World Health Organisation (2013).

${ }^{3}$ Mannar and Bohac (2009) and Micronutrient Initiative (2009).
} 
(specifically zinc and vitamin A) as the number one most cost effective potential intervention for advancing global welfare. Specifically, the scholars on the Copenhagen panel estimated that the ratio of benefits (better health, fewer deaths, and increased future earnings) to costs of supplementation would be 17 to 1 . Another package of micronutrient supplementation (iron and iodine) was estimated to be the third most cost effective potential intervention, with a benefit-cost ratio of 9 to $1^{4}$.

Evaluating the effects of large-scale micronutrient interventions in practice on either health or labor productivity is difficult because of problems in measurement and identification. For example, micronutrient interventions often take place at the same time as many other changes in the health and economic environment. Further, as with many other health interventions (for example, bednets for mosquitoes and vaccination), take-up can be correlated with other characteristics that affect health outcomes. Evaluation is particularly difficult in the case of interventions, the benefits of which may not be observable for several decades. In a notable study that takes identification seriously, Field, Robles and Torero (2009) exploit delays and gaps in the implementation of the iodization program in Tanzania in order to identify a within-district (and within-household) effect on school grade attainment. They find that treatment of mothers with iodated oil resulted in a rise in schooling of 0.33 years among children, with a larger effect for girls than boys.

In this paper we study the long-run effects of iodine fortification in the United States ${ }^{5}$. Iodine is of particular interest for several reasons. First, it is among the "big three" micronutrients, deficiencies in which are a major source of ill health in developing countries (the other two are vitamin A and iron). Second, the most important effects of iodine deficiency are on the cognitive development of fetuses in utero, and these effects are not reversible later

\footnotetext{
${ }^{4}$ Copenhagen Consensus Center (2008).

${ }^{5}$ In using historical data from a developed country to study what is now viewed as a development issue, we are following along the lines of Bleakley (2007), who examined the effects of hookworm eradication in the American South in early 20th century and finds significant effects on education and future incomes of those cohorts that benefited from the intervention. Similarly, Ferrie, Rolf and Troesken (2012) finds that increases in lead exposure through water pipes resulted in lower test scores among US Army recruits during World War II and Watson (2006) finds that improvements in sanitation of Indian reservations in the 1960's explain a big part of the convergence in infant mortality rates between Whites and Native Americans.
} 
on in life. Thus one would expect the benefits of iodization in terms of adult health to be apparent only many decades after the rollout of the intervention. Third, because iodine deficiency affects mental development, the elimination of this deficiency is a candidate explanation for part of the Flynn Effect, the gradual rise in measured IQ over many decades that has been observed in developed countries. Finally, iodization is interesting because it was the first case of blanket food fortification in the US, and to some extent set the pattern for other interventions that followed (vitamins, iron, etc.). As we show below, the benefits of iodization were large, but there were also very significant health costs (several thousand premature deaths) associated with the program.

We identify our estimates by looking at an interaction of geographic variation in iodine deficiency with a national program of salt iodization. Iodine deficiency is linked directly to geography through the food and water supply. In adults, the most noticeable symptom of iodine deficiency is goiter, the enlargement of the thyroid gland. Prior to salt iodization, endemic goiter and other iodine deficiency disorders were present in specific regions of the US and absent from others, depending on the iodine content of the soil and water. Figure 1 illustrates the geographic distribution of goiter in the US as measured among World War I recruits (we discuss the data further below). In 1924 iodized salt was introduced in the United States explicitly to reduce the goiter rate. This intervention rapidly reduced the incidence of iodine deficiency. Since there are large in utero effects of iodine deficiency, we should see a significant difference between those born before and after the introduction of iodized salt in locations with low levels of environmental iodine. Those living in high iodine regions provide a control group.

We exploit two unique data sources to look at the effects of iodine deficiency eradication on cognitive ability. After World War I, statistics from draft physicals were compiled by geographic location. From this source we know the incidence of goiter for 151 geographic regions before the introduction of iodized salt. This provides us with a measure of iodine deficiency prior to treatment. 
Figure 1: Distribution of goiter during World War I

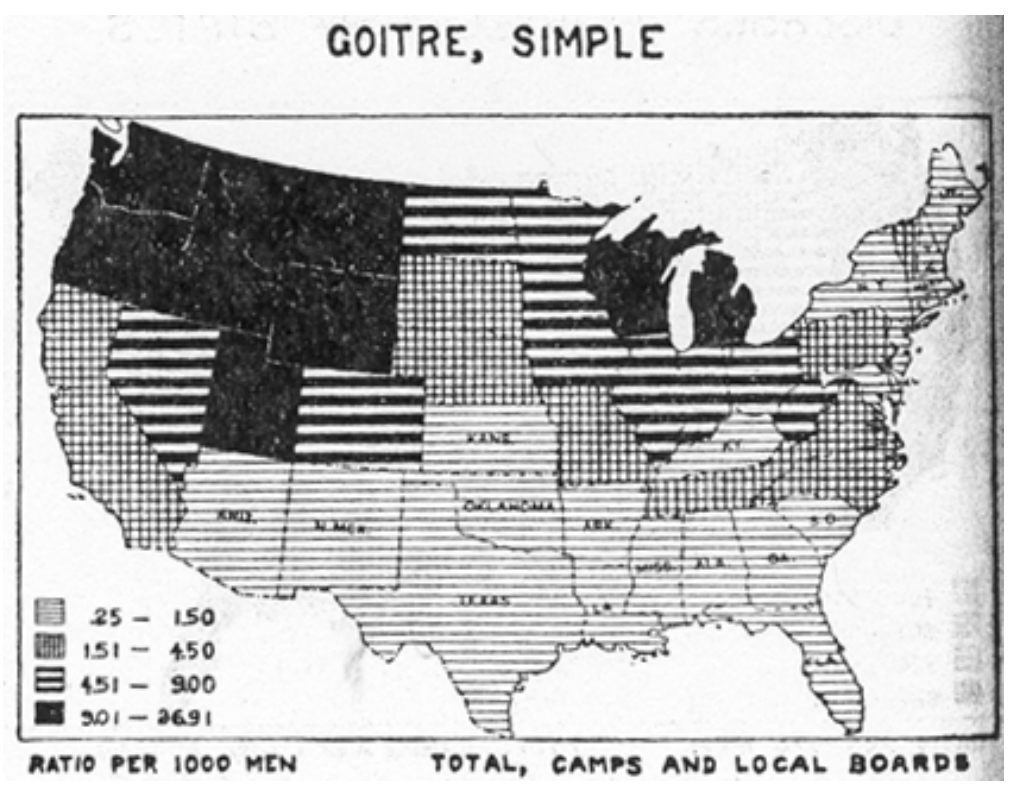

Source: Love and Davenport (1920)

Our outcome measure is provided by an extensive dataset of men who enlisted in the Army during World War II. The timing of the war generates a large sample of men born in the years 1920-1927, neatly covering the introduction of iodized salt. Upon enlistment, each recruit took the Army General Classification Test (AGCT), a forerunner to the AFQT. The Air Forces were assigned draftees with significantly higher average test scores than the Ground Forces. We exploit this non-random assignment in our identification strategy. The probability of assignment to the Air Forces rises significantly in low iodine (i.e. high goiter) counties in the years after the introduction of iodized salt. In the lowest iodine regions, our estimates suggest a 2.5-8.7 percentage point increase in the probability of a man being assigned to the Air Forces after iodization.

Using information about average scores of Air and Ground Force recruits we can infer a one standard deviation increase in average test scores in these regions. The average level of iodine deficiency in the US was significantly lower than in the highest regions, so the overall effect in the US was much more modest. The increase in cognitive ability due to salt 
iodization may have contributed to the rise in measured IQ that took place over the course of the twentieth century, the so-called "Flynn Effect".

In addition to the positive cognitive effects of iodizing salt we document a significant negative side effect. Chronic iodine deficiency, followed by a sudden large intake of iodine, can cause iodine-induced hyperthyroidism, which can be fatal. We show that there was a large rise in thyroid-related deaths in iodine deficient regions following the introduction of iodized salt. We estimate that at least 10,000 deaths over the period 1925-1942 were the result of iodization. These deaths affected mostly older age groups, which had been deficient for a longer period of time.

The paper proceeds as follows: Section 2 provides some background on iodine deficiency disorders. Section 3 outlines the history of salt iodization in the US. Section 4 describes our data and provides some background on their collection. In Section 5 we present previously undocumented evidence on the spike of thyroid-related mortality following iodization. Section 6 explains our identification strategy and section 7 presents our results. Section 8 interprets our results and puts them in the context of related research on the effects of iodization on cognitive ability. Section 9 concludes.

\section{Iodine Deficiency Disorders}

Recent work has shown that the quality of maternal health and nutrition during pregnancy has persistent effects on adult health outcomes. For instance, Almond (2006) shows that cohorts exposed to the Spanish Influenza of 1918, either in utero or during the first months of life, had worse health and socio-economic outcomes in their lifetime. Behrman and Rosenzweig (2004) find that differences in birth weight among identical twins are reflected in differences in school attainment and adult earnings ${ }^{6}$.

Iodine is one of the "big three" micronutrients, deficiencies in which are a major source of ill health in developing countries (the other two are vitamin A and iron). Iodine deficiency,

\footnotetext{
${ }^{6}$ For an excellent review of the literature, see Almond and Currie (2011)
} 
in particular, is the leading cause of preventable mental retardation in the world. WHO estimates that nearly 50 million people suffer some degree of mental impairment due to iodine deficiency ${ }^{7}$. 1.88 billion people -nearly one third of the world's population- are at risk, in the sense that their iodine intake is considered insufficient. 241 million school-age children receive inadequate amounts of iodine in their diet (Andersson, Karumbunathan and Zimmermann 2012).

Iodine Deficiency Disorders (IDD) is a term used to describe a set of conditions, ranging from goiter to cretinism, that result from inadequate intake of iodine. Around $70-80 \%$ of the total iodine content in the human body is found in the thyroid gland (Fleischer, Forbes, Harriss, Krook and Kubota 1974). The thyroid gland uses iodine to produce thyroxin, a hormone that regulates the metabolism. When there is too little iodine in the diet, the thyroid enlarges, forming a goiter. This enlargement (governed by thyroid stimulating hormone produced by the pituitary gland in response to low thyroxin) allows the thyroid to produce more thyroxin for a given availability of iodine, and can fully or partially compensate for the shortage of iodine. When dietary iodine is only slightly inadequate, the enlarged thyroid will be able to produce sufficient thyroxin for normal body functioning. This is known as euthyroid goiter. At lower levels of dietary iodine, the enlarged thyroid will produce inadequate thyroxin, a condition known as hypothyroid goiter, characterized by slow metabolism, lethargy, and weight gain.

In most individuals with goiters due to iodine deficiency, an increase in dietary iodine will result in the thyroid gland returning to its normal size and thyroxin production remaining at or returning to its proper level. However, in some people with this condition, increased iodine consumption results in the thyroid gland producing excessive quantities of thyroxin, resulting in hyperthyroidism. This is called iodine-induced thyrotoxicosis. Hyperthyroidism is characterized by an overly accelerated metabolism, with symptoms including rapid heart-

\footnotetext{
${ }^{7}$ source: WHO, http://www.who.int/features/qa/17/en/index.html.
} 
beat, weight loss, temperature elevation, nervousness, and irritability ${ }^{8,9}$. The problem of iodine induced thyrotoxicosis is most likely to occur in individuals who have experienced long periods of iodine deficiency and those with "nodular goiter". Nodular goiter represents a later stage of the disease; it is preceded by diffuse enlargement or simple goiter ${ }^{10}$.

Beyond goiter and the associated effects of iodine on the metabolism, a second effect of iodine deficiency occurs in utero. Iodine deficiency early in pregnancy causes serious brain damage to the foetus. Unlike the effects of goiter, this damage is permanent. Severe iodine deficiency can result in cretinism, which is characterized by "profound mental deficiency, dwarfism, spastic dysplasia and limited hearing" (Scrimshaw 1998, p.364) ${ }^{11}$. In endemic areas cretinism can affect up to $15 \%$ of the population (de Benoist, Andersson, Egli, Takkouche and Allen, eds 2004). However, as Scrimshaw points out, "even in areas where cases of cretinism due to iodine deficiency in the mother are few, the linear growth of the infant, its intellectual capacity, and certain other of its neurological functions are permanently compromised to varying degrees" (Scrimshaw 1998, p.351). In other words, even if iodine deficiency does not result in cretinism, an iodine-deficient region will be marked by the lower cognitive performance of its population. Deficient populations typically see a leftward shift in the entire IQ distribution ${ }^{12}$. Bleichrodt and Born (1994), conducting a meta-analysis of 18 studies, estimate that the average IQ of iodine-deficient groups is 13.5 points lower than the non-deficient groups. While widely cited, this result is based primarily on simple observed cross-sectional comparisons, which makes the identification of a causal effect questionable.

\footnotetext{
${ }^{8}$ Reference: "Goiter" in Health A to Z, www.healthatoz.com

${ }^{9}$ Goiter and hyperthyroidism can also result from Graves Disease, also called Basedow disease, an immune condition in which the thyroid is stimulated to produce excess thyroxin.

${ }^{10}$ Iodine-induced thyrotoxicosis is also called Jod-Basedow disease. "Jod" is German for iodine. The name indicates that iodine consumption is resulting in the symptoms of Basedow disease. Examining the rise in thyroid disease that followed the introduction of iodized bread in Tasmania, Connolly (1971) found that most patients with iodine-induced thyrotoxicosis had pre-existing nodular goiter, and few had Graves disease.

${ }^{11}$ According to one interpretation, the word cretin comes from the French term for Christian. Cretinism was endemic in the French Alps, where the term was apparently invented for those who were too mentally limited to commit a sin and who, therefore, were good Christians.

${ }^{12}$ Scrimshaw (1998) provides a list of studies and experiments that have been conducted, and which have shown the hindering effects on mental development of iodine deficiency in utero.
} 


\subsection{The Incidence and Treatment of Iodine Deficiency Disorders}

In economies where the diet is composed primarily of locally produced food, the main determinant of whether a population will be iodine-deficient is geography. Ocean water is rich in iodine, which is why endemic goiter is not observed in coastal areas. From the ocean, iodine is transferred to the soil by rain. This process, however, only reaches the upper layers of soil, and it can take thousands of years to complete (Koutras, Matovinovic and Vought 1980). Heavy rainfall can cause soil erosion, in which case the iodine-rich upper layers of soil are washed away. The last glacial period had the same effect: iodine-rich soil was substituted by iodine-poor soil from crystalline rocks (Koutras et al. 1980). This explains the prevalence of endemic goiter in regions that were marked by intense glaciation, such as Switzerland and the Great Lakes region of the USA. Iodine is taken up by plants when it is present in the soil, and can reach humans either through plants or animals which have eaten them. Iodine is also present in subsurface water in some locations. Finally, deposits of mineral salt (the remains of evaporated seawater) contain iodine, but this is lost when the salt is refined. The human body does not naturally store a great deal of iodine, so that seasonal variations in iodine consumption may result in seasonal manifestations of IDD.

Even before the discovery of iodine, ancient civilizations treated goiter with burnt sponge or seaweed (Curtis and Fertman 1951, Langer 1960). After iodine was discovered in 1811 by Courtois, continuous clinical research for over a century proved its essential role as a measure of prophylaxis against IDD. Doctors and public health officials have used different methods to ensure that adequate quantities of iodine are provided for a given population. Salt iodization has proved to be the cheapest and most wide-reaching way to protect a population from iodine deficiency. Alternatives have included the iodization of water supplies and bread, as well as the provision of iodine-enriched chocolates or milk to babies and schoolchildren and injections of slow-releasing iodated oil ${ }^{13}$.

\footnotetext{
${ }^{13}$ Iodization of water supplies proved wasteful since only a small proportion of water is used for drinking and cooking purposes. Bread iodization was used in the Netherlands as a wartime measure (Matovinovic and Ramalingaswami 1960).
} 


\section{Iodine Deficiency and Salt Iodization in the United States}

It was only in the last century that micronutrient deficiencies were eliminated in the United States and other developed countries. Pellagra, a deficiency in niacin that results from diets dependent on maize, was endemic in the US South at the beginning of the twentieth century. Rickets, a bone-deforming disease caused by deficiency of vitamin D, was common in industrial cities of the North. Both diseases were controlled by a combination of dietary improvements and fortification. Vitamin D was added to milk in the 1930s, and B vitamins (including niacin) were added to baked goods starting in the 1940s (Bishai and Nalubola 2002). Salt iodization was the first experiment in the systematic fortification of food to combat micronutrient deficiency. This public health intervention was made possible by the nearly simultaneous discovery of a widespread health problem and of its underlying cause.

In the First World War draft, a little more than 2.5 million draftees were examined for various physical and mental shortcomings. From these examinations a lengthy collection of countrywide data was compiled, showing the geographic distribution of many diseases and defects across the United States (Love and Davenport 1920). Goiter was among the defects that were measured, because an unexpectedly high number of soldiers had trouble wearing a uniform because of their enlarged thyroids.

According to the draft examinations almost 12,000 men had goiter and a third of these were judged unfit for service, because the size of their neck was too big for the military tunic to be buttoned (Kelly and Snedden 1960, p.34). Most of them came from states in the Northwest (Washington, Oregon, Idaho, Montana) and the area around the Great Lakes. In Northern Michigan, for instance, more draftees were judged unfit for service "for large and toxic goiters than for any other medical disorder" (Markel 1987, p.221). On the other hand, goiter was rare in people coming from coastal areas.

The realization of the problem led to multiple surveys of goiter, which confirmed the 
geographical variation in the prevalence of the disease. By that time, there was medical and veterinary evidence showing that goiters could be reduced by adding iodine to the diet. Experiments with school children confirmed that the size of goiters decreased after receiving iodine ${ }^{14}$. These observations prompted a public debate on the possible ways to provide iodine prophylaxis to the American population. Some objections were raised as to the potential side-effects of such a global measure. It had been documented that large amounts of iodine could cause hyperthyroidism to develop in some adults and thyrotoxicosis in others. Despite these concerns, the medical consensus was that small amounts of iodine in the diet were beneficial for the vast majority of an iodine-deprived population, and this was confirmed by the experimental results in schoolchildren.

Public health authorities in Michigan, one of the worst-afflicted states, held a symposium on thyroid disease in 1922. The idea of salt iodization (which had been proposed by researchers in Switzerland, and was first implemented in that country in 1922) was introduced by David Murray Cowie, M.D. as a cheap and effective means of providing iodine to all population groups, regardless of social status. As a result, the Iodized Salt Committee was set up, with the mission of investigating the matter further. The Committee, chaired by Cowie, produced reports on the low iodine content of drinking water in Michigan and the possibility of effective prevention of goiter through iodized salt. Its members agreed upon the launch of a statewide educational campaign on goiter and its prevention though iodized salt, sponsored by the Michigan State Medical Society. The campaign, launched in 1922, included lectures to physicians and the general public delivered across the state.

The Committee also contacted the state's salt manufacturers. The salt producers, although convinced about the public-service character of the project, had initial qualms about its economic feasibility and profitability; it would be financially impossible to separate the salt intended for the Michigan market and then add iodine to it. Instead, the Salt Producers Association decided to launch iodized salt nationwide; they saw the new product as an

\footnotetext{
${ }^{14}$ The first such experiment took place in Akron, Ohio in 1917, under the direction of David Marine and O.P. Kimball. For details see Marine and Kimball (1921), and Carpenter (2005).
} 
improved commodity for which there would be a much larger market -and corresponding profits- than that of Michigan. As a result, in May 1924, Michigan was the first state to introduce iodized salt ${ }^{15}$. The actions of the Michigan salt producers were important, because Michigan was the largest producer of salt for human consumption in the country ${ }^{16}$.

The salt companies contributed to the educational campaign through aggressive advertising of the "new salt" throughout the country, in order to create a market for the new product (Markel 1987, p. 224). Figures 2 and 3 shows two ads from this period. Figure 4 is a copy of a newspaper clipping from the era.

After Michigan introduced iodized salt, the penetration of the new product was quite rapid. McClure (1934) reports that as of 1930, $89 \%$ of total salt sales in Michigan were iodized. As mentioned above, salt producers made the new product available nationwide, since this was the only way that the project would be financially feasible. Morton Salt Company, the largest producer in the country at the time, began selling iodized salt on a nationwide basis in the fall of $1924^{17}$. At the same time, public awareness of the problem, especially in those areas that were worst afflicted, was gaining momentum. Articles in newspapers and magazines around the country advocated the use of the new salt for all cooking and eating purposes, making references to successful goiter prophylaxis in Switzer-

\footnotetext{
${ }^{15}$ Before that, in April 1923, public authorities in Rochester, New York, introduced iodine in the water supplies of one reservoir, in what is known as "the Rochester experiment" (Kohn 1975). Subsequent goiter surveys show an important decrease in incidence. However, it seems unlikely that this decrease was due to the iodization of the water supply, for the following reasons: first, only one of the reservoirs was iodized. Second, by that time, iodized salt was available and widely used in Rochester. Third, because of bigger awareness and improved medical monitoring, doctors were more likely to prescribe iodine supplements to anybody with a palpable goiter.

${ }^{16}$ Salt production takes three forms: evaporated, rock salt, and the production of liquid brine. In 1924 the quantities produced by these three methods were 2.22, 2.06, and 2.51 million short tons, respectively. Brine was used exclusively as a feedstock by the chemical industry. According to the Salt Institute (http://www.saltinstitute.org), as of today, virtually all food grade salt sold or used in the United States is produced by evaporation. This was the case in 1924 as well (personal communication from Richard Hanneman, President, Salt Institute, March 6, 2008). In 1924, Michigan was the largest producer of evaporated salt in the country, accounting for $36 \%$ of total salt production. The next largest producers were New York $(18 \%)$ and Ohio (14\%) (Katz 1927).

${ }^{17}$ (Markel 1987). Collusion in the evaporated salt industry was widespread, and Morton acted as the price setter. Many companies literally made copies of Morton's price schedule, simply replacing their company letterheads for that of Morton (Fost 1970). Morton's decision to iodize salt in 1924 would thus likely have affected a large percentage of households, both directly and through Morton's influence on smaller companies.
} 
Figure 2: Morton's advertisement for iodized salt

\section{Goiter strikes 1 out of 3 Prevent it with}

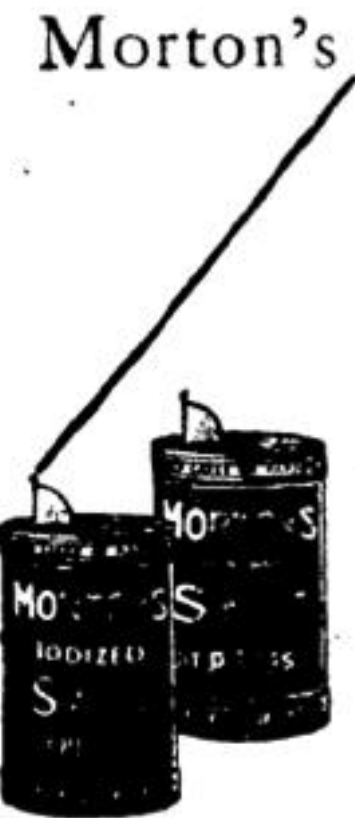

Alike - exeept obe contein IODINE

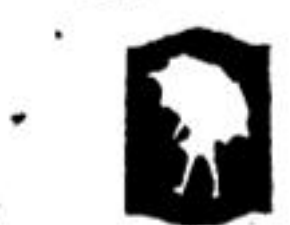

FEIT under is escape this health sapping, deforming malady-yet none need suffer.

For iodized salt prevents - guiter. The Swiss stamped out goiter thus.

Morton's Indized Salt is the salt approved everywhere by physicians.

Be safe-get Morton's-it tastes no different. It was prepared at the request of high medical authorities-it must be right.

Ask for Morton's Iodized Salt at your grocer's.

Write Dept. 205 for

FREE BOOK

MORTON $\underset{\text { SHLAT COMPANY }}{\text { SALT }}$

\section{WHEN IT RAINS-IT PIIIRS \\ MORTON'S SALT}

Source: "The Bee", Danville, Virginia, May $11^{\text {th }} 1925$ 
Figure 3: Mulkey's advertisement for iodized salt

\section{FOR THE PREVENTION OF SIMPLE GOITER}

Read what the Heaith
Officers of West Virginia
Say about lodized Salt

The oxelusive use of Iodised Sait by people living in goiterous diatriets will have a far teaching effect in the prevention of simple Goiter. I feet that peretail grocer who Goiter. I feet shat exelusely in out gol hanales lodiecd Salt exclusely in our gol terous sections of the United States is reader. ing an invaluable service to his patrons and to the community."

$$
\text { M. V. ZIEGLER, M. D. }
$$

1 Director Divisian of Promteble Diseases West Virginie Deftatsment of Heath

Dr. W. T. HENSHAW, the State Commin sioate of Health, West Virginia, says: "He is pleaned to know that the sali manufacturen have senen fic to comply with the recommes. fatlons of the Michiean State Medicat Society

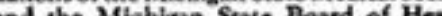
and the Michiman seace Boand of Heatu et an lodised Salt for the prevention of simple Goites"

Girls are more subject to Goiter than are boys. $A$ bulletin issued by the

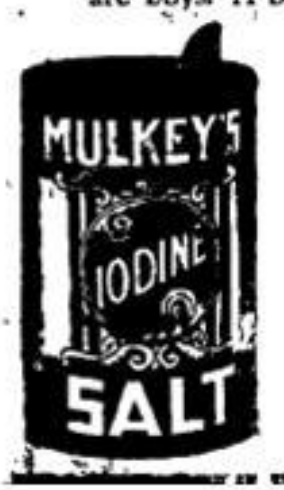
Health department states that in one town in West Vir. ginia 50 per cent of the girls have goitci; in another 56 per cent; in another 80 per cent; aridy 1 h another 64 per befit.

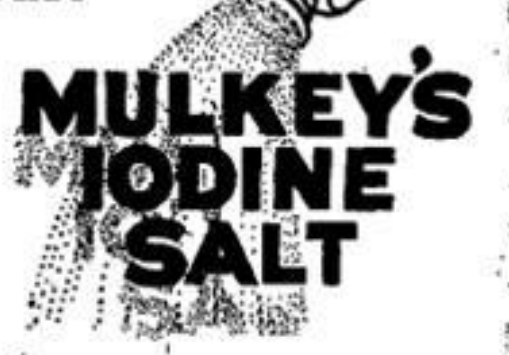

For prevention' of simple Goiter the same bulletin recommends: "Every girl in West Virginia should kèeb her thyroid gland saturated with lodtine between 'the ages 'of eleven' ant fixteen inclusive."

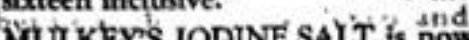
available to every family. It is produced in co-operation' with'this grtat public health movenient- the eradication of Goiter.

A'k your grocer for MÜLKEY's 10. DINE SALT; if not in stock he can set it for you.

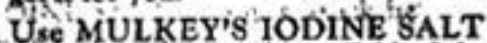
just as you do ordinary Table Salt. No difference in the tiste, color or scasoning quality of the Salt.

Our pamphlet en Geater asiled frice nopin requent

MULKEX'SALT COMPANY DETROIT, MICHIOAN

Source: "Middlesboro Daily News", Kentucky, June $14^{\text {th }} 1924$ 
Figure 4: A newspaper article discussing iodized salt

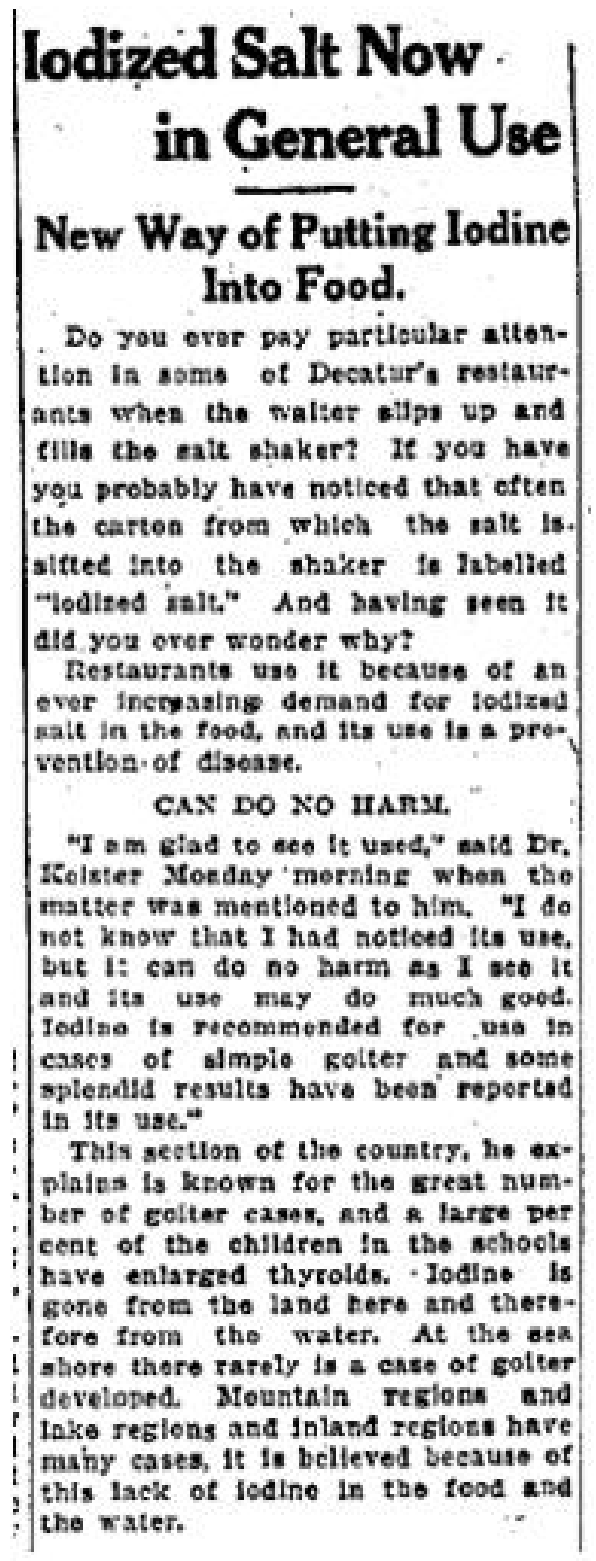

Source: "The Decatur Review", Illinois, December 1"st 1925 
$\operatorname{land}^{18}$. Most state health authorities urged the public to use iodized salt. In advertisements of iodized salt, the new commodity bore the endorsement of state or national medical associations and educational booklets were provided by the salt companies upon demand. We have not been able to find precise numbers on the penetration of iodized salt (or other iodine dietary supplements) for the rest of the country, but all the evidence suggests that the new product became very popular very quickly, especially in the goiter-belt region, where it mattered the most. We have many newspaper sources that show the generalized availability and use of iodized salt from 1924 onwards. In addition, as we show in section 5, the rapid rise in thyroid-related mortality, not only in Michigan but throughout the country, further indicates that iodine supplementation diffused quite rapidly.

The focus of the salt iodization campaigns was goiter eradication. It is not clear that the link between iodine deficiency and mental function was suspected at the time. The decrease in mental retardation that resulted from iodization campaigns was a very positive unintended consequence. These cognitive benefits are the main motivation for modern iodization campaigns (though goiter remains the most obvious sign of an iodine deficient population).

\section{Data Sources}

We wish to examine the impact of the iodization of salt in 1924. In order to do so, we need two pieces of information. First, who was likely to benefit from salt iodization? Second, how did the outcomes of these individuals change after the iodization of salt in $1924 ?$

As previously described, the presence or absence of endemic iodine deficiency depends on the iodine content of the soil and ground water. Individuals born in low iodine areas are much more likely to be iodine deficient than those born in high iodine areas. Iodizing salt will have a large effect on the former and no effect on the latter. The abrupt switch to

\footnotetext{
${ }^{18}$ For example: Lima News (Lima, Ohio), on August 29, 1924, reports that iodized salt is now marketed "thru the regular grocery trade". In Appleton Post Crescent (Appleton, Wisconsin), on January 28, 1926, it is mentioned that "iodized salt is now sold by grocers everywhere, and families can use it instead of ordinary salt".
} 
iodized salt completes the natural experiment. Individuals born in high iodine areas should see no effect from salt iodization. Individuals born in low iodine areas, by contrast, should see effects whose size is related to the severity of iodine deficiency before the treatment. The latter group provides our treatment group and the former group our control.

To implement this strategy we need data on the prevalence of iodine deficiency before 1924, as well as data on outcomes of individuals born in these areas both before and after 1924. Our primary data sources take advantage of two previously unused surveys of prime age American males in the early part of the twentieth century; we use data collected during the military drafts of World War I and World War II.

\subsection{Defects in Drafted Men}

For data on the prevalence of iodine deficiency before 1925 we use a volume entitled Defects Found in Drafted Men, published by the War Department in 1920 (Love and Davenport 1920 $)^{19}$. Defects summarizes the results of all the physical exams performed on draftees during World War I for both accepted and rejected men. Data on prevalence rates per 1,000 are recorded for 269 different medical conditions. The data are regional, organized by units called sections. All but the lowest population states are broken down into multiple sections. Illinois and New York, for example are broken down into 8 sections. Each section is defined as a collection of counties ${ }^{20}$. In total, Defects has data on 151 separate regions of the country. Figure 5 is a map of the US showing the locations of sections from Defects.

The medical condition of interest for our study is simple goiter, which is a direct result of iodine deficiency. We use simple goiter as a proxy for iodine deficiency. Simple goiter is relatively common in the data, with a population weighted average prevalence of about 5 cases per 1,000 and a median prevalence of 2.5 per 1,000 . The prevalence rates range as high as 29.85 cases per 1,000. Though there are no sections with a zero rate of simple goiter,

\footnotetext{
${ }^{19}$ Many thanks to Hoyt Bleakley for making us aware of this marvelous book.

${ }^{20}$ Since county borders in the US are relatively static, it is straightforward to map the Defects sections to present day US counties.
} 
Figure 5: Sections of U.S. counties in World War I

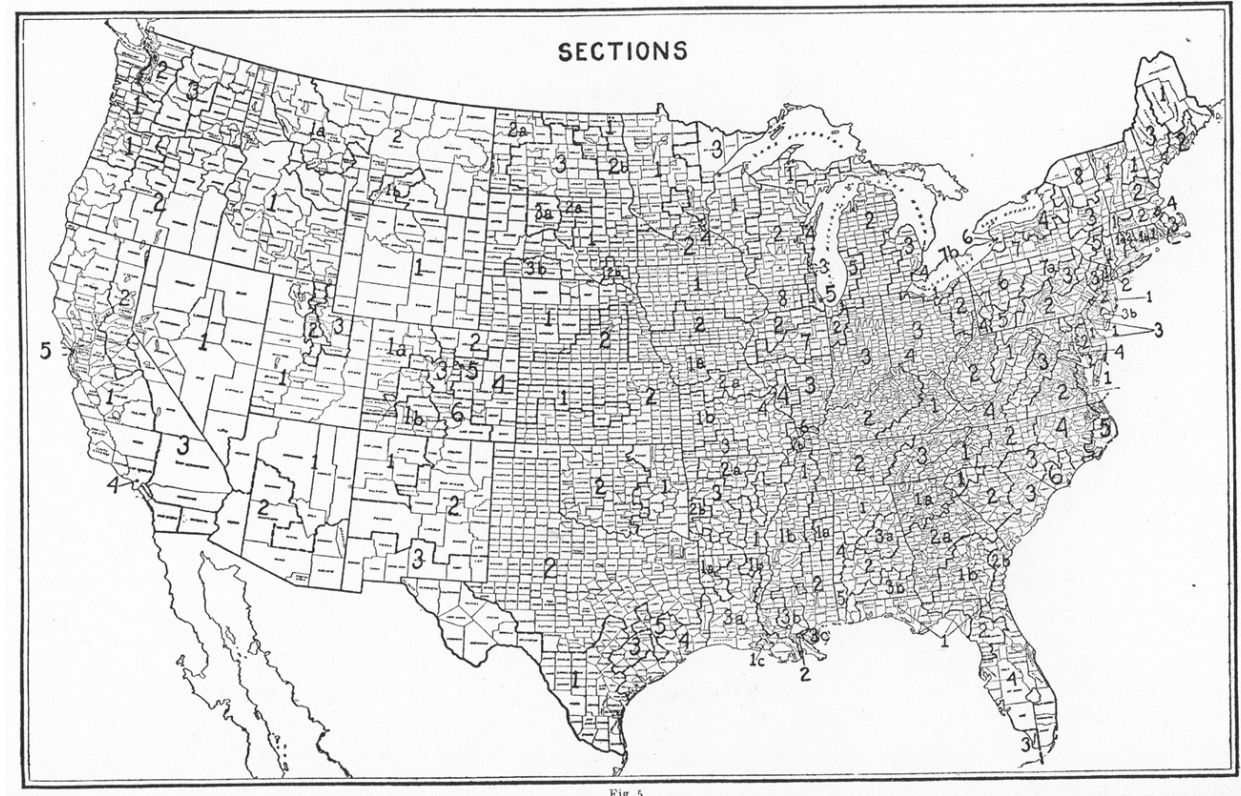

source: Love and Davenport (1920)

about one third of the sections have rates of less than 1 per 1,000 . Figure 6 shows the simple goiter rate at the state level. Rates range from a high of almost 27 per 1,000 in Idaho to a low of 0.25 per 1,000 in Florida.

The fact that the data are at a finer level of aggregation than the state level is important because there is significant regional variation within the high goiter states. For example, in the five sections in Michigan the rates reported in Defects range from over 25 in the Upper Peninsula to less than 10 in Detroit and the surrounding areas.

The incidences of iodine deficiency identified in Defects are almost certainly geographic in origin. In a paper published in the Journal of the American Medical Association in 1924, J.F. McClendon and Joseph C. Hathaway provided measures of the iodine content of drinking water from 69 localities across the US ${ }^{21}$. These measures came from lakes, springs, rivers and wells. Their paper includes US maps with the low-iodine areas being shaded, and other maps where the high-goiter areas are shaded (their data on goiter come from the Defects

\footnotetext{
${ }^{21}$ Parts of Iodine per hundred billion parts of drinking water.
} 
Figure 6: Simple goiter rates by state, as recorded during World War I draft TABLE 18.-Grand total for goiter, simple, with ratio per 1,000 men.

\begin{tabular}{|c|c|c|c|c|c|}
\hline State. & $\begin{array}{l}\text { Number } \\
\text { of cases. }\end{array}$ & $\begin{array}{l}\text { Ratio per } \\
1,000 .\end{array}$ & State. & $\begin{array}{l}\text { Number } \\
\text { of cases. }\end{array}$ & $\begin{array}{c}\text { Ratio per } \\
1,000 .\end{array}$ \\
\hline 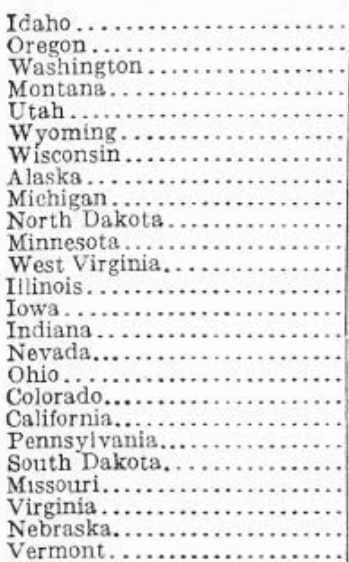 & $\begin{array}{r}336 \\
421 \\
832 \\
570 \\
185 \\
102 \\
886 \\
16 \\
1,131 \\
156 \\
578 \\
307 \\
1,397 \\
458 \\
464 \\
21 \\
798 \\
119 \\
359 \\
829 \\
85 \\
342 \\
188 \\
63 \\
18\end{array}$ & $\begin{array}{l}26.91 \\
26.31 \\
23.40 \\
21.00 \\
15.72 \\
15.37 \\
14.02 \\
13.14 \\
11.43 \\
8.73 \\
8.04 \\
7.89 \\
7.79 \\
6.68 \\
6.49 \\
6.38 \\
5.59 \\
5.29 \\
4.45 \\
4.10 \\
4.09 \\
3.99 \\
3.38 \\
2.14 \\
2.14\end{array}$ & 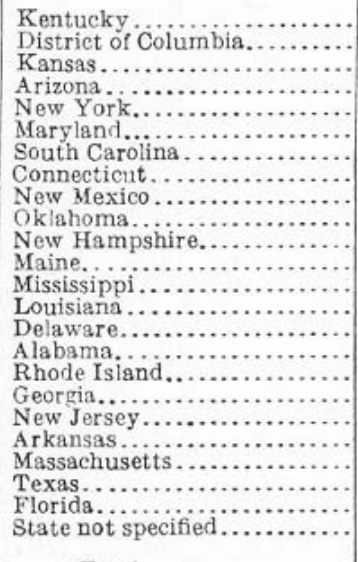 & $\begin{array}{r}90 \\
16 \\
48 \\
10 \\
308 \\
35 \\
37 \\
32 \\
9 \\
44 \\
6 \\
13 \\
24 \\
32 \\
3 \\
29 \\
8 \\
33 \\
33 \\
17 \\
29 \\
36 \\
6 \\
186\end{array}$ & $\begin{array}{r}1.41 \\
1.39 \\
1.25 \\
1.21 \\
1.19 \\
.94 \\
.94 \\
.89 \\
.88 \\
.72 \\
.70 \\
.66 \\
.64 \\
.62 \\
.59 \\
.55 \\
.55 \\
.52 \\
.43 \\
.40 \\
.32 \\
.30 \\
.25 \\
1.96\end{array}$ \\
\hline 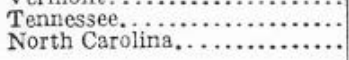 & $\begin{array}{l}120 \\
100\end{array}$ & $\begin{array}{l}1.96 \\
1.81\end{array}$ & To & 11,971 & 4. 35 \\
\hline
\end{tabular}

source: Love and Davenport (1920)

Figure 7: Distribution of goiter rates at the section level, as recorded during World War I draft

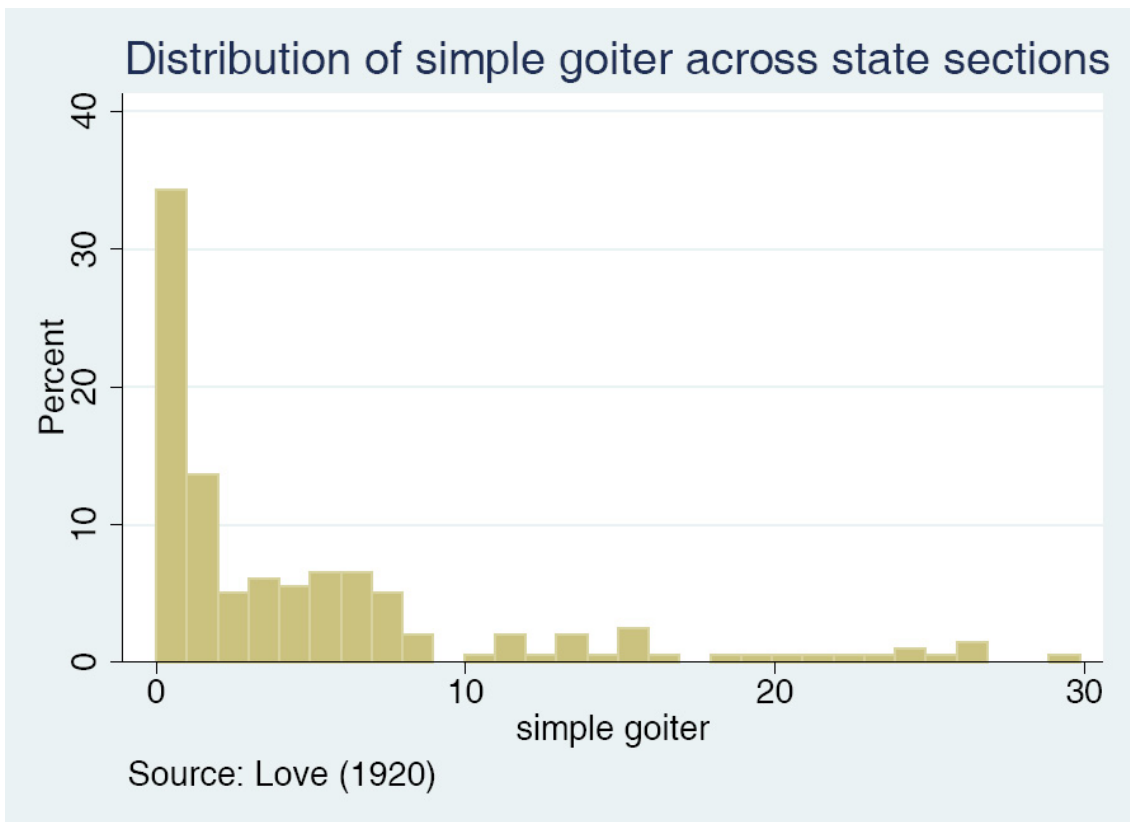


Figure 8: Pre-iodization distribution of goiter rates among World War II recruits, as recorded during World War I draft, based on their county of origin

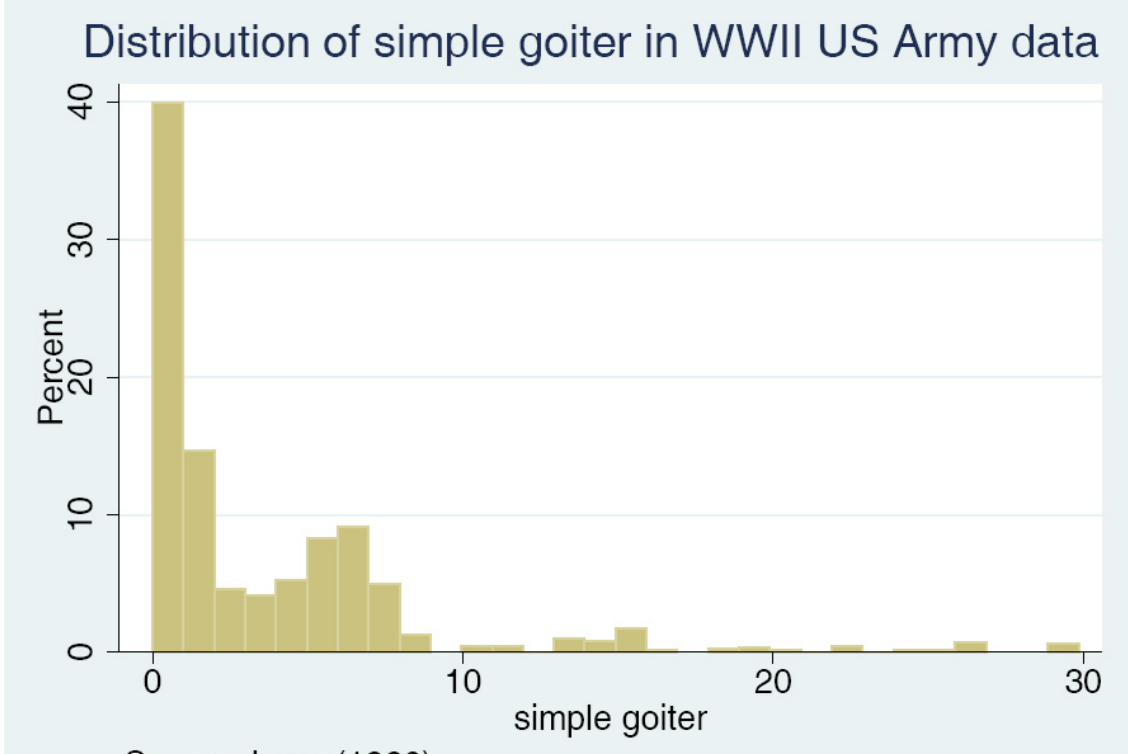

Source: Love (1920)

Figure 9: Goiter and iodine content of water

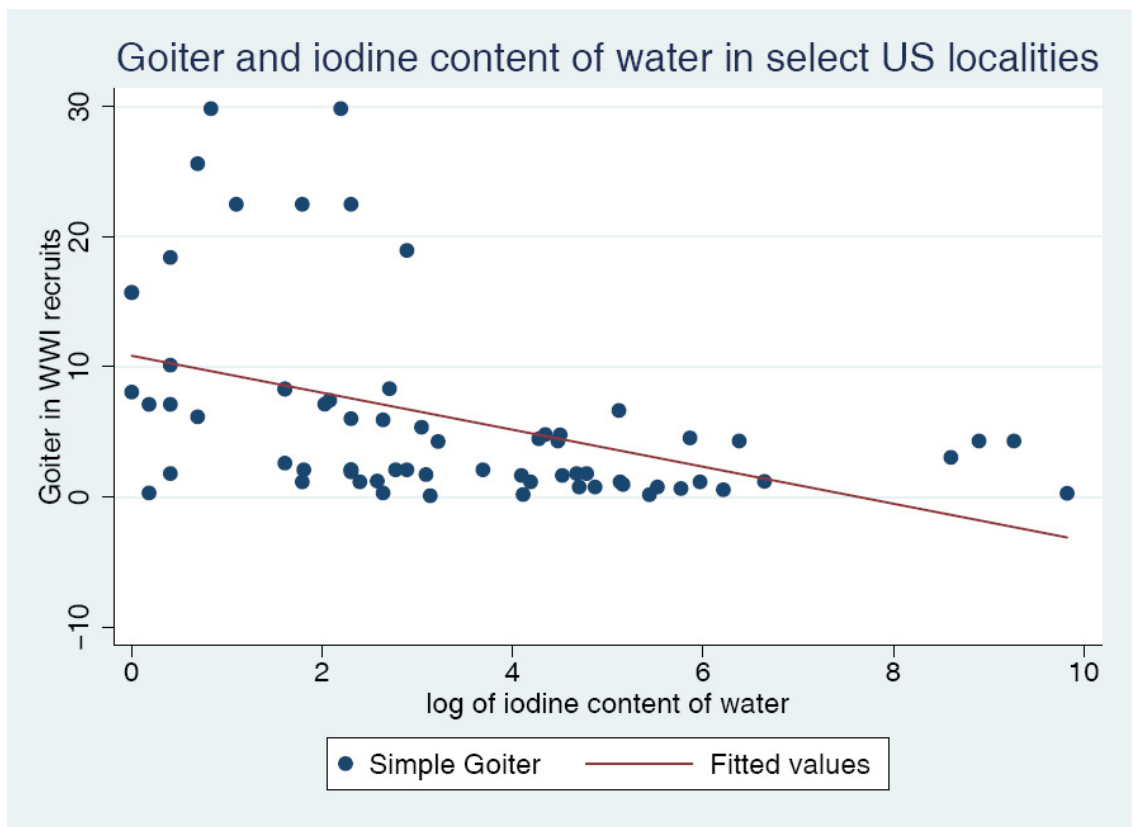

source: McClendon (1924) and Love and Davenport (1920) 
Book). The two shaded areas in the two maps largely overlap (McClendon 1924). The data on the iodine content of water are not plentiful enough to be used as alternative measures of iodine deficiency, in addition to the goiter data that we have. They are useful, however, because the negative correlation between the iodine content measures and the goiter in their section of origin suggests that goiter variation was due to geographical factors. Figure 9 is a scatterplot relating the log of iodine to the level of simple goiter in the section where the origin of the water sample belongs (typically a town).

We expect that the effect of iodizing salt will be larger in areas where the prevalence of goiter in Defects is highest. Since the medical literature suggests that the largest impact of iodine deficiency is in utero, we would like to identify individuals born in high and low goiter areas both before and after 1924. Luckily for our purposes, the United States government performed a survey of this population during the draft for World War II.

\subsection{World War II Enlistment Data}

The World War II enlistment data are from the National Archives and Records Administration (NARA). The data has its origin in punch cards produced during the enlistment process for the United States Army, including the Women's Army Auxiliary Corps. It includes both volunteers and draftees. After the war these punch cards were converted to microfilm. In 1994 NARA hired the census department to scan the microfilm into a collection of over 9 million enlistment records from 1938-1946. Though not complete, these records represent the majority of the enlistment into the Army during this period. Of the 1,586 rolls of microfilm, 1,374 (87\%) were successfully scanned, leaving approximately 1.5 million punch cards unrecorded. The missing rolls are not sequential, and there are no indications that the records are missing in any systematic fashion. In addition to the missing rolls, several hundred thousand individual records were unreadable. As far as we know, the only other study to date using this data is Ferrie et al. (2012) which studies the effect of lead exposure on the outcome of World War II enlistees. 
Though the format of the punch cards changed somewhat over the course of the war, the coding for basic demographic information was consistent. The demographic fields are name, serial number, state and county of residence, place and date of enlistment, place and year of birth, race, education, and marital status. In addition, the particular branch of the Army that the enlistee entered is coded. One can also infer through the serial number whether the person was drafted. There are no records for individuals who entered the Navy or Marines.

The sample we have available to us is obviously very large and the timing of the draft is nearly perfect for our purposes. Limiting our sample to white men, we have data on over 300,000 from each birth year between 1921 and 1927, giving us extremely complete coverage on both sides of the 1924 salt iodization date. Unfortunately, the data do not include the county of birth, only the state. We therefore limit our sample to individuals whose birth state is identical to their state of residence and we assume that the county of residence upon enlistment is the county of birth ${ }^{22}$. This reduces the sample by less than half, leaving us with almost 2 million records of individuals born between 1921 and 1927.

\subsection{Test Scores and Assignment to the Air Forces}

All enlistees were given the Army General Classification Test (AGCT), a predecessor to the AFQT that is currently given to enlistees. This test score would be an ideal outcome for our study, since the primary effect of iodine deficiency in utero is reduced cognitive ability. Unfortunately, the score only appears in our data for a brief time period too early in the war to be useful for our study ${ }^{23}$. We can, however, make some crude inferences about the test scores by examining which army branch the enlistees were assigned to.

Each test taker was assigned a grade of I, II, III, IV, or V, with class I being the highest score on the test and $\mathrm{V}$ the lowest. Jobs within the Army were deemed to require soldiers from different groups. For example, skilled positions like mechanics tended to get class I or

\footnotetext{
${ }^{22}$ Classical measurement error in the county of birth will introduce attenuation bias in our estimates, which should therefore be seen as lower bounds.

${ }^{23}$ See Ferrie et al. (2012) for a more detailed description of AGCT scores in the NARA data.
} 
Table 1: Percent of enlistees assigned to the Army Air Forces by year.

\begin{tabular}{lc}
\hline Year & Percentage in Air Forces \\
\hline 1940 & 13.7 \\
1941 & 32.6 \\
1942 & 18.8 \\
1943 & 03.8 \\
1944 & 10.8 \\
1945 & 13.9 \\
1946 & 19.1 \\
Total & 14.0 \\
\hline Source: National Archives and \\
Records Administration (2002)
\end{tabular}

II enlistees, while lower skill jobs, like cooks tended to get class IV or V enlistees. We do not know the particular job assignment of each recruit. However, we can identify enlistees who were assigned to the Army Air Forces (AAF) versus those who were assigned to the Army Ground Forces (AGF) ${ }^{24}$ Roughly $14 \%$ of all enlistees were assigned to the AAF over the course of the war, though this proportion varied from year to year. The year to year variation is described in Table $1^{25}$.

Table 2 is a summary of our enlistment data. It gives the total sample size and the percentage of recruits going to the Air Forces for each cohort and each enlistment semester. The number of enlisted men started increasing in 1942, and it peaked in the second semester of that year, as well as the first semester of 1943. People born after iodization enlisted in large numbers starting the first semester of 1943. The proportion of recruits going to the Air Forces was particularly low in 1943.

\footnotetext{
${ }^{24}$ During World War II military aviation was part of the Army and not a separate branch. The Army Air Forces were established in June of 1941 as a semi-autonomous group within the Army. Prior to this reorganization the aviation wing of the Army was known as the Army Air Corps. We will refer throughout to the Army Air Forces even though our data span this renaming.

${ }^{25}$ The year to year variation is largely driven by changes in US participation in the war. In 1941, the US was largely engaged in the Air War and had less need for ground forces. By 1943 the need for ground forces rose considerably.
} 
These AAF enlistees were systematically different than other enlistees during the war. There is ample evidence that the AAF enjoyed preferential assignment of inductees compared to other Army branches ${ }^{26}$. This is discussed in more detail below.

\footnotetext{
${ }^{26}$ See, for example, Palmer, Wiley and Keast (1948, p.21)
} 


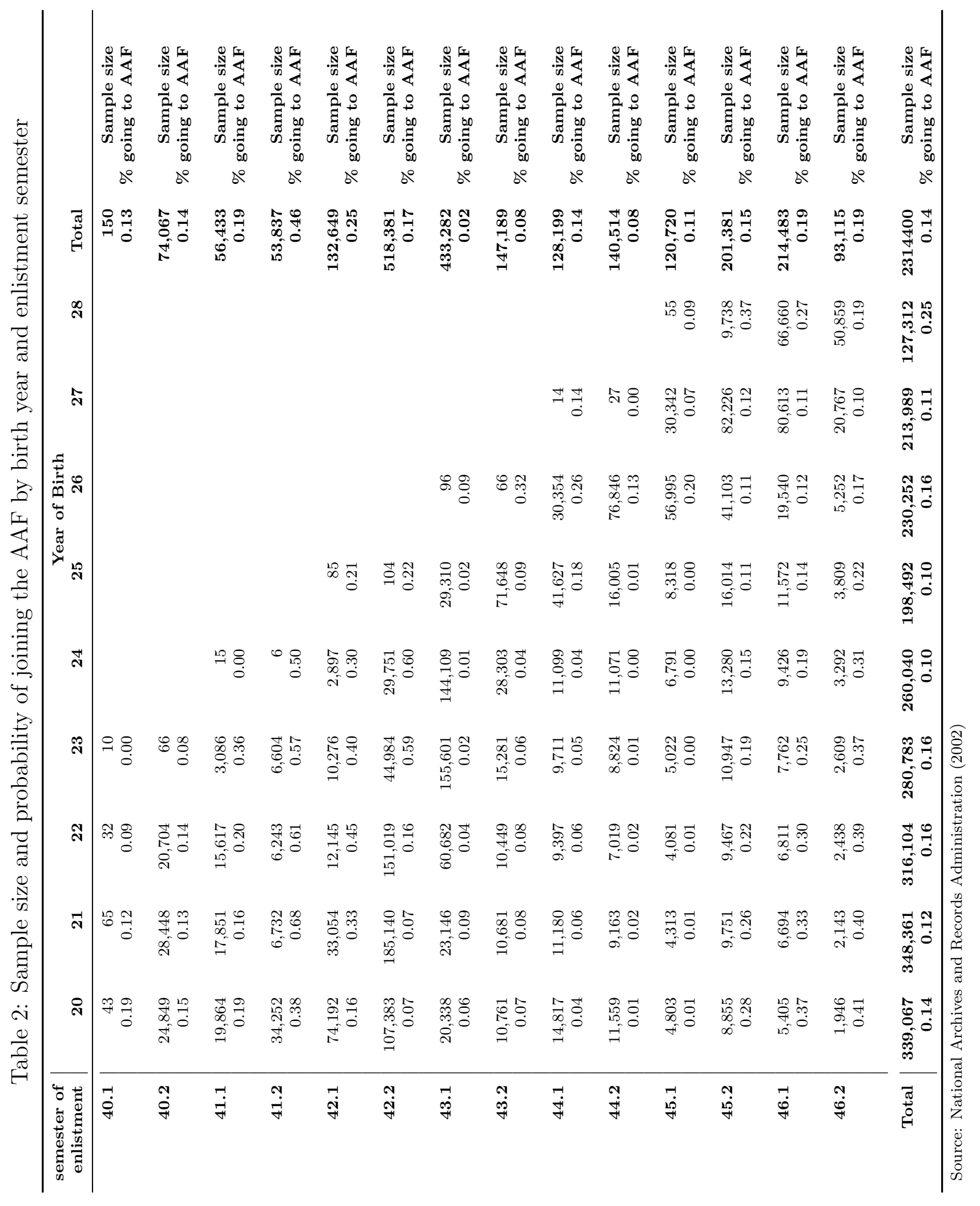




\subsection{The Battle for the Best Enlistees}

The Army Air Forces (AAF), which was still part of the Army during World War II, had a large proportion of jobs that required skilled recruits relative to the Army Ground Forces (AGF). Throughout the war, the AAF pushed to have a large proportion of the more highly skilled recruits assigned to the Air Forces. In February 1942, the AAF successfully got the 75 percent rule put into place. Under this rule, 75 percent of the men assigned to the AAF were to have scored above 100 (the median score) on the AGCT ${ }^{27}$. From this, we can infer that individuals assigned to the AAF during this period have, on average, higher test scores than those assigned to the AGF. Because the AGCT is a normalized exam, we can even infer how much higher this average was.

Unsurprisingly, the AGF was not pleased with this arrangement, and this rule was not in place for the entire war. Though lower skilled recruits could easily be used in the infantry, the AGF was concerned about having a supply of recruits who could become high-quality combat leaders. The AGF successfully lobbied the War Department to change the rule on August 1, 1942 so that the proportion of above average men received by the AAF was reduced to 55 percent $^{28}$.

The AAF fought back against this change by using a second test, the mechanical aptitude (MA) test, as a screen for AAF recruits. At first, they simply requested that a higher proportion of men assigned scored above average on the MA test. This was later formalized. From December 1942 until June 1943, the AAF was supposed to be assigned 55 percent of their new recruits from the group with scores greater than the mean on both the AGCT and the MA tests. Combining the two tests was obviously more restrictive than just using one test. In fact only 37.5 percent of all recruits were above average on both tests ${ }^{29}$. This rule was allowed to expire, but it is clear that the AAF continued to get higher quality

\footnotetext{
${ }^{27}$ US Air Force Historical Study \#76, Classification and Assignment of Enlisted Men in the Air Arm 1917-1945, p. 44.

28 ibid, p.46.

29 ibid, p.56.
} 
Figure 10: Percentage of Air Forces Recruits with above average AGCT scores

\section{PERCENTAGE OF RECRUITS PROCESSED WEEKLY AT BASIC TRAINING CENTERS WITH G C T STANDARD SCORES OF IOO OR MORE}

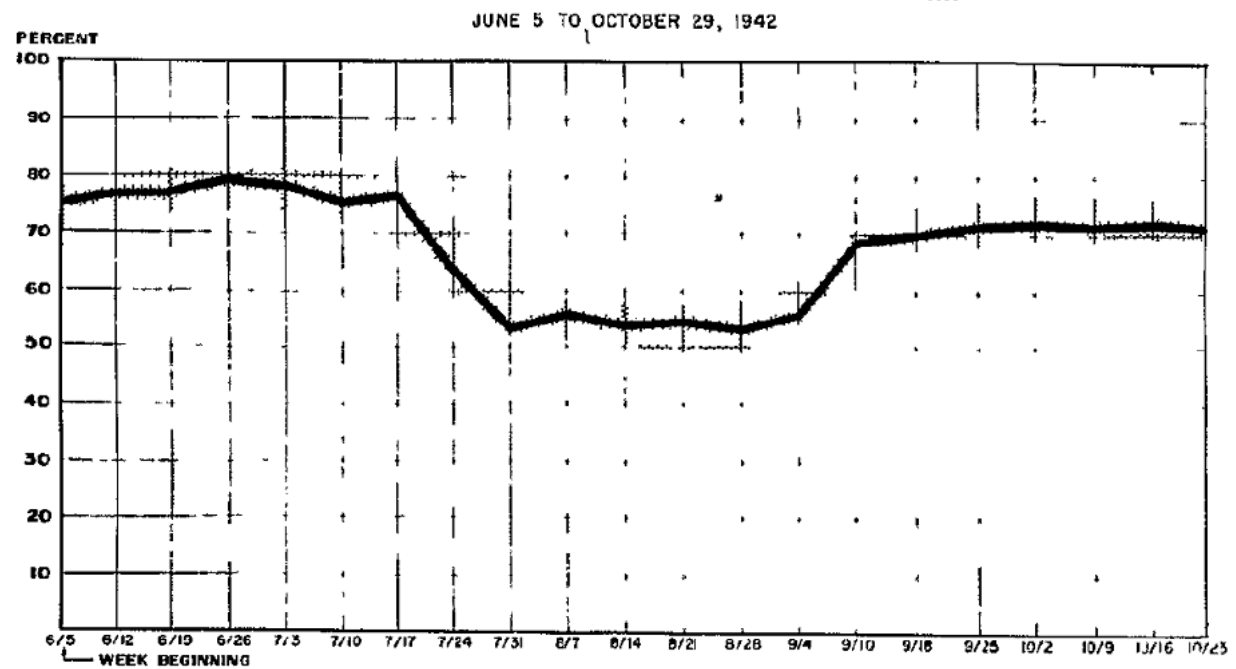

source: US Air Force Historical Study \#76:

Classification and Assignment of Enlisted Men in the Air Arm, 1917-1945.

of recruits even after the rule formally expired. For example, for those inducted in 1943, $41.3 \%$ of soldiers assigned to AAF were class I or II. This percentage is higher than the one corresponding to Ground Combat Arms (29.7\%) and Services (36.5\%) [data come from Palmer et al. (1948)].

Figure 10 is a graph from the War Department showing the percentage of recruits assigned to the AAF with above average AGCT scores during the period of time that these rule changes were occurring. During the early part of the graph, the 75 percent rule was clearly in operation. At the end of July, the abolition of the 75 percent rule can be seen, with the AAF only getting 55 percent of recruits from the above average group. By September, the AAF had managed to return to the old proportions via the 55 percent mandate on both the AGCT and MA tests.

Additional evidence on the positive selection of men with high cognitive function into the AAF comes from an anomaly in the WWII enlistment data. As mentioned above, all new enlistees in the army took the AGCT test, but this test result was not generally recorded on 
the punch cards that are the primary source for the enlistment data. However, from March to May 1943, AGCT scores were recorded in the fields marked "weight" for almost all recruits ${ }^{30}$. The fact that AGCT was coded in this field for some subset of the war is suggested in the documentation. Observing the actual distribution of values in the "weight" field confirms this is true for a subset of observations. Examining observations from enlistments through 1942, the weight field has a mean of 147 and a standard deviation of 28. For the period of March through May of 1943, the mean is roughly 106 and the standard deviation is about 80. Once we eliminate values which are below 20 and over 180, which clearly do not correspond to test scores (3.7\% of observations), the mean becomes 98 and the standard deviation 21 . These numbers are very close to the intended mean and standard deviation of the $\mathrm{AGCT}^{31}$.

Figure 11 shows a histogram of AGCT scores for recruits entering the Air Forces alongside a histogram for all other recruits. ${ }^{32}$ For the non Air Forces group there are 175,731 reported scores with a mean of 97.7 and a standard deviation of 21.1. This distribution matches the normal distribution of the AGCT (which was supposed to have a mean of 100 and standard deviation of 20). The second panel shows the histogram of recruits entering the AAF in this period. The mean (124.1) suggests that the AAF was, at this point, receiving substantially better recruits than the ground forces. However, as seen in Table 2, this was also a period in which very few recruits entered the Air Forces. This histogram is based on only 541 AAF recruits $^{33}$.

The preferential treatment of the AAF lasted until the end of 1943, when the "infantry

\footnotetext{
${ }^{30}$ Many thanks to Joe Ferrie for pointing this out to us.

${ }^{31}$ We must also note that correlation of the "weight" field with education is much stronger for this limited time period, at about $65 \%$, compared with no correlation for the rest of the sample. This strong correlation, however, is only true for cohorts born up to 1925. It drops to $35 \%$ for the 1926 cohort, which only consists of 28 observations. There are no observations for the 1927 and 1928 cohorts.

${ }^{32}$ We only include values between 20 and 180, which are realistic test score values. The vast majority of observations (96.3\% of the sample) are in this range. In addition, because the recording of AGCT scores in this field was for such a short period of time, there is some question as to whether all enlistment places coded this field the same way. For this reason we also drew the histograms using only data from enlistment places with over 500 recruits and where the mean of the weight field is between 80 and 120 within the enlistment place. This eliminated less than 11,000 observations and did not substantially change the distributions.

${ }^{33}$ Out of the 541 recruits who were assigned to the Air Forces over that period, none of them was born in 1926 or later, and only 37 individuals were born in 1925 .
} 
Figure 11: AGCT Scores for AAF versus all other enlistees

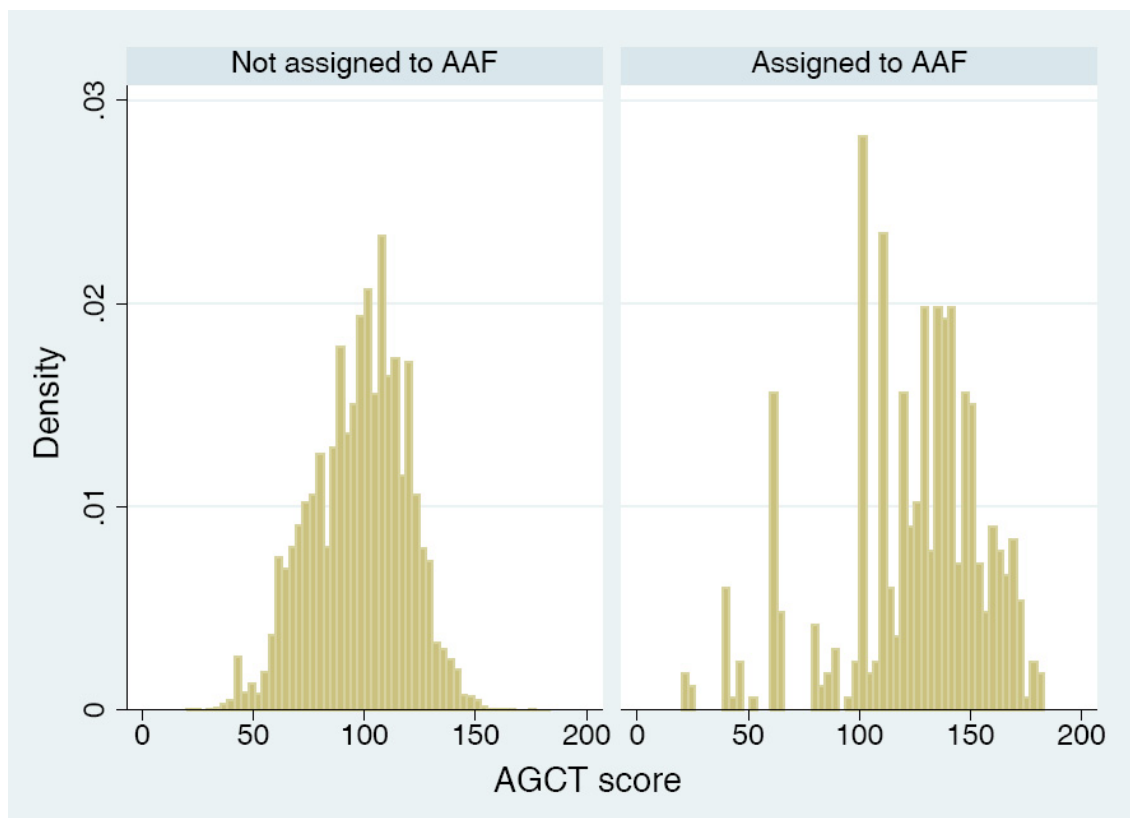

source: National Archives and Records Administration (2002)

crisis" broke out. The need for high-quality ground forces grew more acute in 1944 and lasted until the end of the War, while, at same time, air operations were not as important as in previous years. This meant that priorities between the AAF and the AGF shifted in favor of the latter, and the Army classification system was revised to allow for better-quality soldiers to join the Ground Forces ${ }^{34}$. With this classification procedure, as well as with tranfers within the Army commands, the AGF had an influx of high-quality men, especially in the end of 1944 and afterwards, as opposed to the Air Forces. At the same time, the distribution of recruits among the Army commands changed, and most of the new inductees were assigned to the Ground Forces.

Through our enlistment records we know whether or not an individual was assigned to the AAF or the AGF. We know that individuals assigned to the AAF have higher test scores

\footnotetext{
${ }^{34}$ The New classification procedure was based on "The Physical Profile System", which became operative in 1944, and classified recruits into three profiles, according to their ability to withstand strenuous combat conditions. $80 \%$ of men assigned to the AGF had to belong to the top profile, whereas only $10 \%$ of the AAF recruits came from the top group.
} 
than the average enlistee for the initial phase of the war. We can also see the selection into the AAF over the course of the war by looking at the proportion of high school graduates assigned to each branch. Table 3 gives the proportion of high school graduates in each branch by birth year. Figure 12 shows the proportion of high-school graduates by enlistment month, separately for the Air Forces and the rest of the Army.

Table 3 shows that the younger cohorts were less likely to have a high-school degree than the older cohorts. This is because, as the war progressed, the demand for manpower led to the drafting of ever younger men. It is also clear that there was positive selection into the Air Forces, which became less pronounced over the course of the war. By the time the 1927 and 1928 cohorts enlisted, the Ground Forces were getting equally, if not better-qualified recruits than the Air Forces. Figure 12 shows the downward trend in the proportion of AAF recruits who had high-school diplomas, which becomes steeper towards the end of 1943, when the infantry crisis broke out and priority was given to the Ground Forces. We can also see from Figure 12 the spike in the proportion of high-school graduates in the Air Forces around February 1942, when the $75 \%$ rule was put into effect. Also, Figure 12 shows the temporary decrease in quality of AAF recruits in the second half of 1942, when the $75 \%$ rule was withdrawn. In late 1942 and early 1943, when the Mechanical Aptitude Test was put into use, the Air Force returned to the preferential-treatment status it enjoyed before.

It is clear that the Air Forces selected higher quality enlistees for the cohorts born from 1920 until 1926. Luckily, this gives us good coverage of pre and post treatment enlistees. As will be seen below, the fact that there was no positive selection into the Air Forces for the 1927 and 1928 birth cohorts is consistent with our empirical results.

We will take advantage of the selection of enlistees into the Air Forces in two ways. First, if iodine deficiency affects cognitive ability we should expect a jump in the relative rate of assignment to the AAF for recruits born after 1924 in those counties where goiter rates were high in the Defects data. Second, by exploiting the normal distribution of the AGCT test, we can interpret our estimation results in terms of IQ gain for those regions where iodine 
Table 3: Percent of high school graduates by birth year and branch.

\begin{tabular}{cccc}
\hline & \multicolumn{3}{c}{ High School Graduation Rate } \\
Birth Year & Air Forces & Ground Forces & Total \\
\hline 1920 & 76.0 & 42.8 & 47.5 \\
1921 & 75.9 & 41.3 & 45.6 \\
1922 & 70.1 & 39.7 & 44.5 \\
1923 & 60.5 & 43.6 & 46.3 \\
1924 & 52.1 & 39.4 & 40.7 \\
1925 & 56.7 & 35.9 & 37.9 \\
1926 & 50.9 & 36.7 & 39.0 \\
1927 & 33.3 & 38.4 & 37.9 \\
1928 & 26.3 & 40.5 & 37.0 \\
Total & 59.1 & 40.1 & 42.8 \\
\hline
\end{tabular}

Source: National Archives and Records Administration (2002)

Figure 12: High-School graduation rates by enlistment month

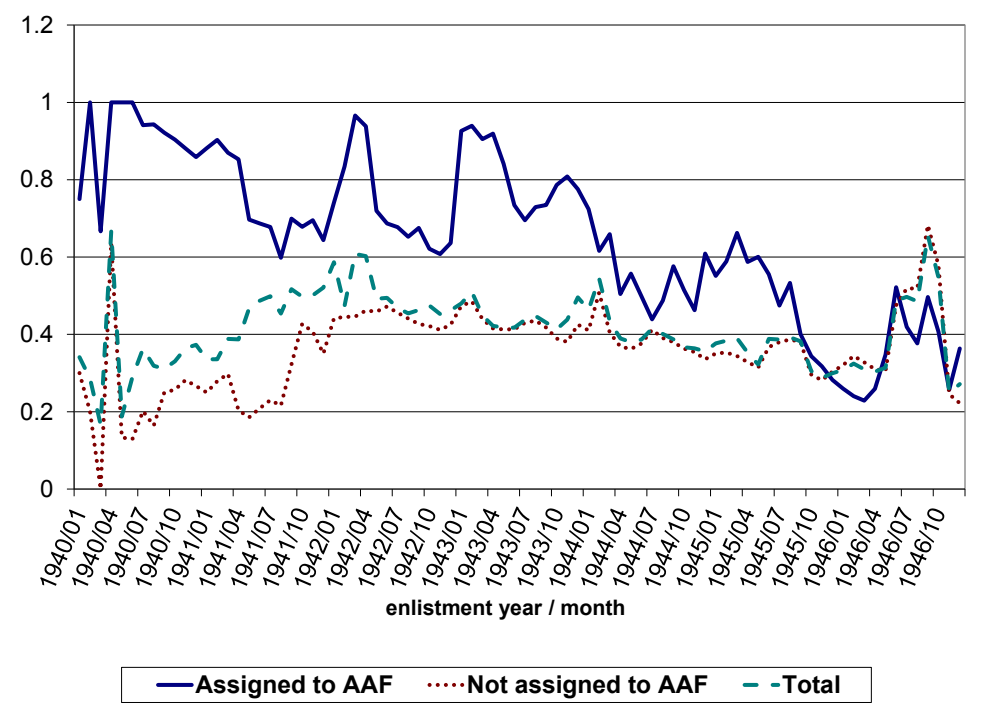

Source: National Archives and Records Administration (2002) 
deficiency was eradicated.

\section{The rise in thyroid-related deaths}

As discussed earlier, the treatment designed to help goiter sufferers sometimes ended up killing them. The doctors and public health officials who worked for the introduction of iodized salt were aware of the potential danger of iodine-induced hyperthyroidism, but viewed the danger as minimal. In Europe, the potential negative side-effects of iodine treatment had been discussed as early as the nineteenth century [see McClure (1934) and Carpenter (2005)] and made universal iodine prophylaxis a controversial public health measure. In this section, we document a large increase in deaths linked to the adoption of iodized salt, which we have not seen previously discussed in the literature.

Figure 13 shows the annual rate of deaths in the US over the period 1910-1960 due to exophthalmic goiter, which accounted for the overwhelming majority of deaths due to thyroid disease over this period. Exophthalmic goiter is an enlargement of the thyroid accompanied by bulging of the eyes, which is sign of hyperthyroidism ${ }^{35}$. There is an extremely large rise in the death rate at the time of iodization. Between 1921 and 1926 the death rate nearly doubled from 2.1 to 4 per 100,000. Deaths due to goiter remained elevated for at least a decade. There was also a large gender disparity in death rates. In 1926 death rates were over 6 times as high for women as for $\mathrm{men}^{36,37}$. The population of the United States in 1926 was 117 million, and so the rise of approximately two deaths per 100,000 people represented an extra 2,340 deaths in that year. Over the period 1925-1942 there appear to be at least 10,000 excess deaths that resulted from the introduction of iodized salt. We have found little discussion in the literature of what appears to be a high short-term price the country paid

\footnotetext{
${ }^{35}$ Source of data: Grove and Hetzel (1968). While some medical dictionaries use the definition stated here, others define exophthalmic goiter as being synonymous with Graves disease, which is the dominant cause of the condition today. It is clear that the definition used in the text was being applied in the vital statistics data.

${ }^{36} 1.1$ per 100,000 for men, 7.0 per 100,000 for women.

${ }^{37}$ Field et al. (2009) finds differential effects between girls and boys in iodine deficient populations in Tanzania
} 
Figure 13: US deaths from exophthalmic goiter, 1910-1960

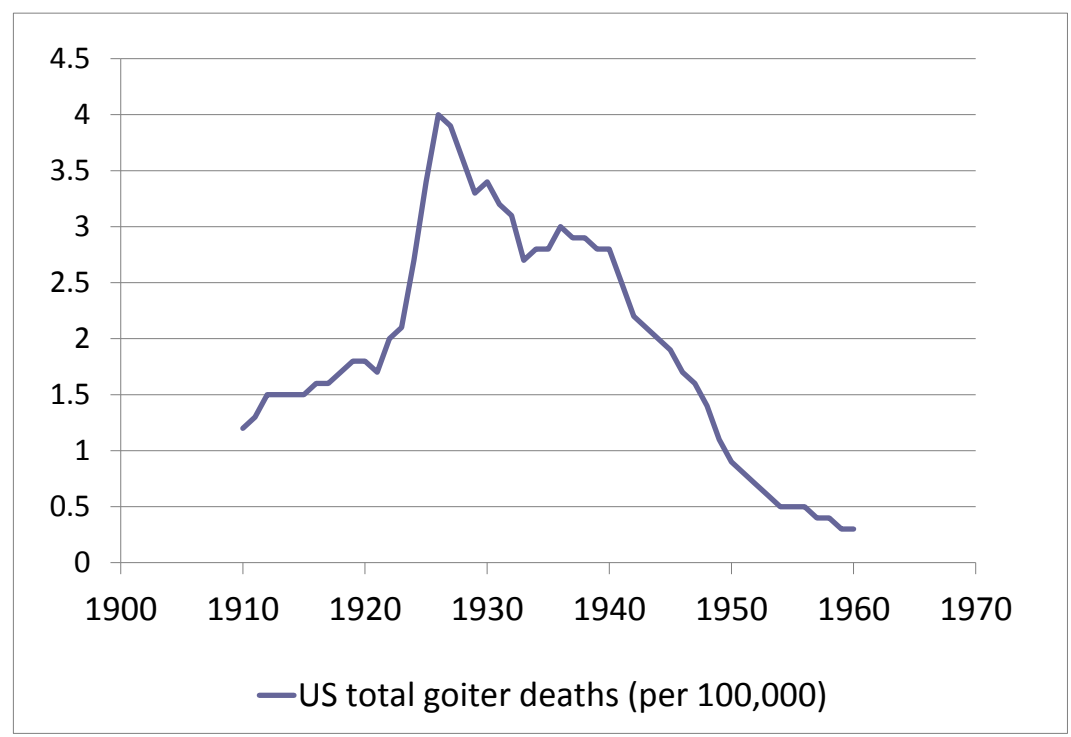

Source: Grove and Hetzel (1968)

for long-run benefits resulting from this public health intervention (an exception is McClure (1934) who notes that goiter deaths in Detroit spiked in the second year following iodization).

As would be predicted by the medical evidence that iodine-induced hyperthyroidism is most common among those with long-standing iodine deficiency, the rise in the death rate was highest, and persisted the longest, among older age groups. As Figure 14 shows, deaths in the 25-34 age category less than doubled from 1921 to 1926, and had fallen below their 1921 level by 1935. In the 65-74 age category, deaths more than tripled between 1921 and 1926, and were still three times their 1921 level in 1935. The link between iodine deficiency and the rise in deaths at the time of iodization is also apparent looking across states. Figure 15 shows a scatter plot of the rate of simple goiter among World War I recruits, which were discussed in the previous section, and the change in the mortality rate from thyroid disease over the period 1921-26. Large increases in mortality all took place in states that had high levels of goiter due to iodine deficiency.

Given the strong evidence that salt iodization caused the rise in thyroid disease deaths, 33 
Figure 14: US goiter deaths by age group, 1921-1935

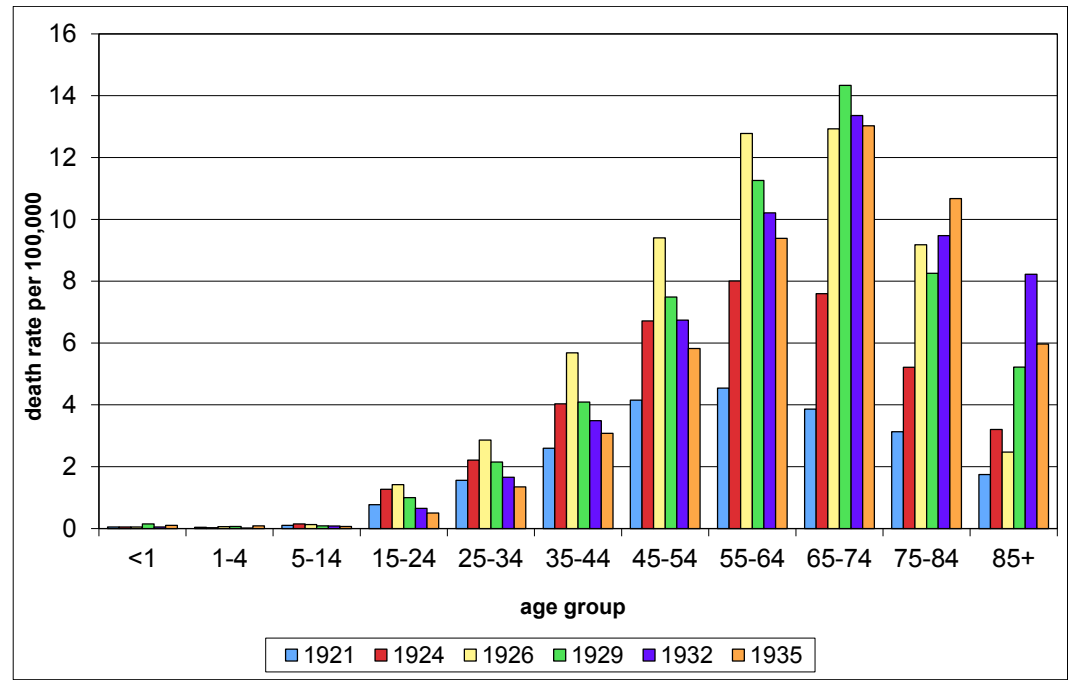

Source: U.S. Department of Commerce (various years)

Figure 15: Changes in thyroid mortality vs. pre-existing goiter rates, 1921-1926

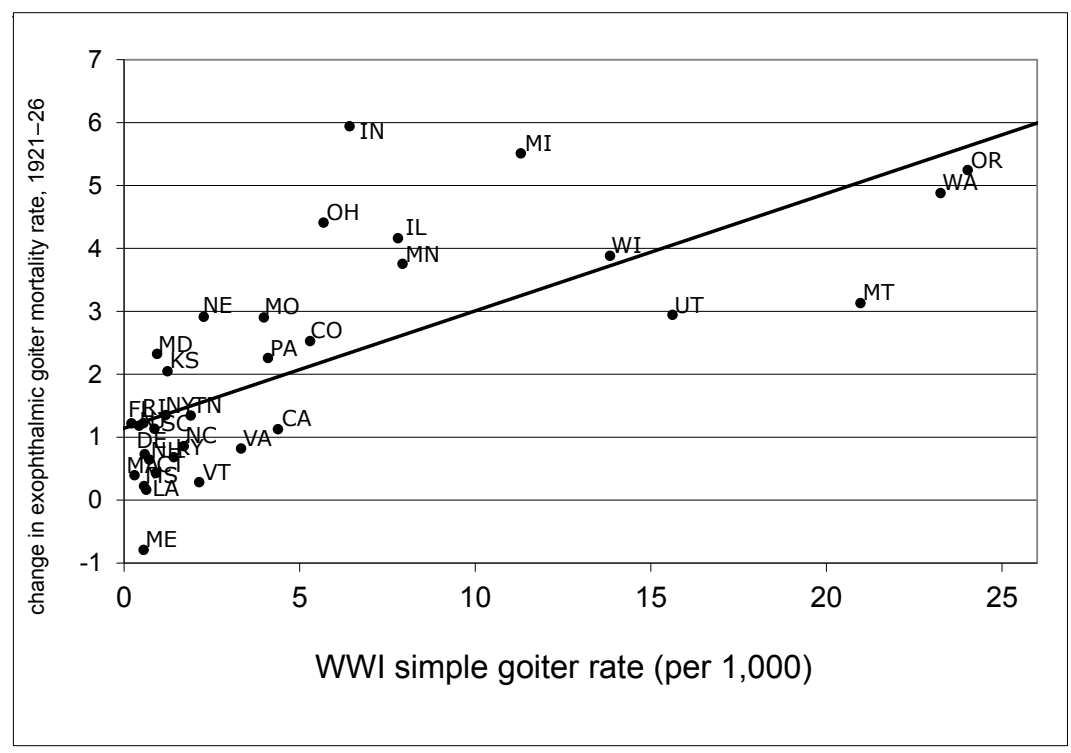

Source: U.S. Department of Commerce (various years) and Love and Davenport (1920) 
Figure 16: Deaths from exophthalmic goiter, Michigan and other states, 1920-1930
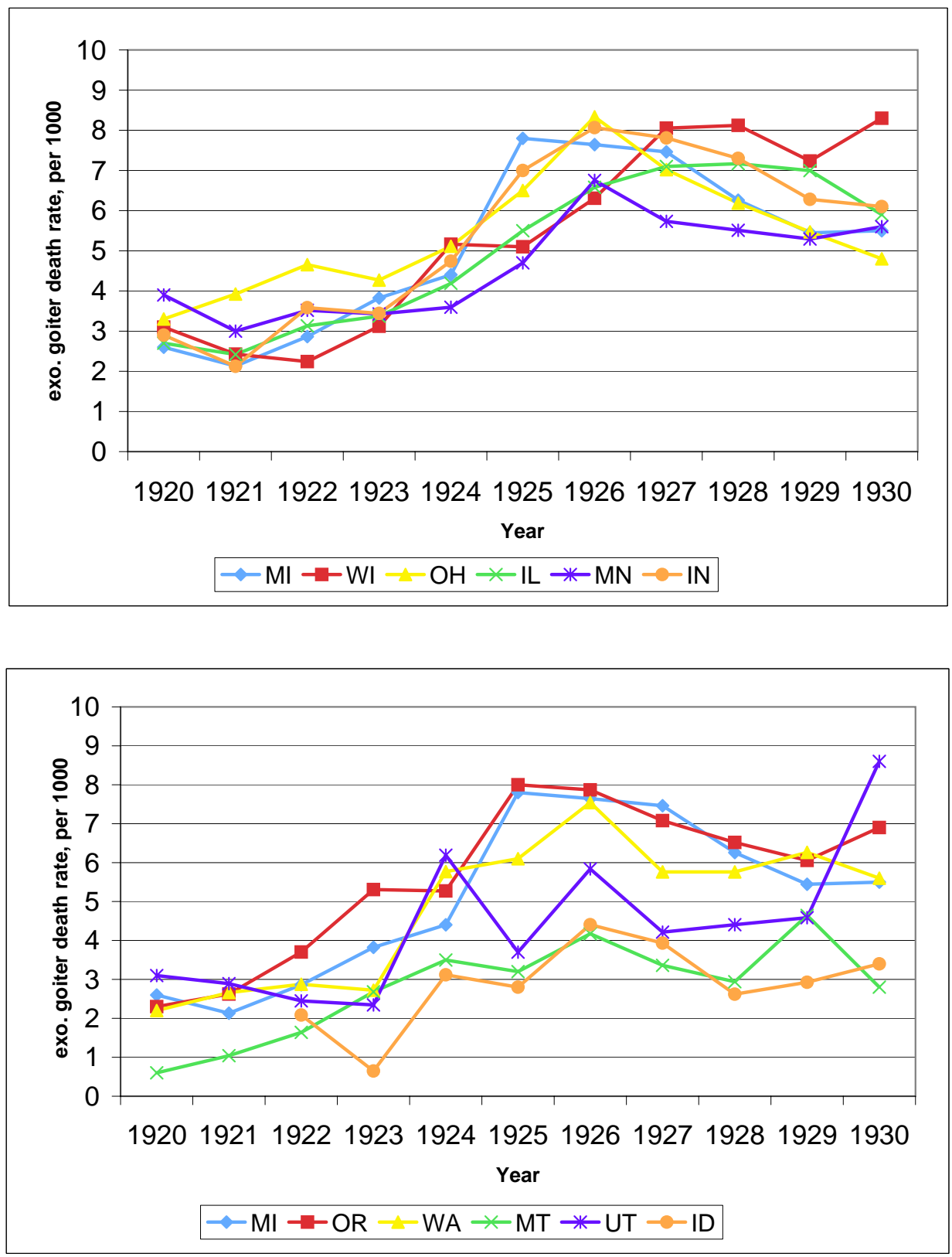

Source: U.S. Department of Commerce (various years) 
we can use data on deaths to learn about the timing of iodization. We do not know the exact time lag between increased iodine consumption and death from thyroid disease in a susceptible person. However, since we know the timing of iodization in Michigan, we can ask whether rises in goiter deaths in the other high goiter states occur at the same time. Figure 16 shows goiter deaths over the period of salt iodization for the 10 high goiter states in the upper right hand quadrant of Figure 15. For clarity, we graph the large states in the midwest separately from the smaller western states, and we include Michigan in both graphs. In Michigan, there is a sharp rise in deaths starting in 1925. This corresponds to the established timing of salt iodization in Michigan. The other high goiter states experience similar timing to Michigan, with some suggestion of a delay in the surge of deaths of a year or less. Because western states are smaller, their data are noisier, but they generally exhibit the same pattern. This suggests that iodization was largely absent in 1924 and widespread by 1926 for the entire country, not just Michigan.

\section{Identification}

Our identification strategy relies on two important sources of variation. The first is the pre-existing extent of underlying iodine deficiecy. In regions where goiter was low among men drafted in WWI, we expect little change after iodizing salt. In regions where goiter was high we expect to see a significant increase in the proportion of men being assigned to the Army Air Forces after iodizing salt. Our second source of variation arises from the timing of the intervention. The rapid introduction of iodized salt provides for a clean distinction between the treated and the untreated. We expect to see a sharp difference between cohorts born before and after 1924. High goiter areas therefore provide the treatment group and low goiter areas the control group. Years before 1924 are pre-treatment and years after 1924 are post-treatment. 
The basic regression specification is:

$$
y_{i}=\alpha+\sum_{t \neq 1924} \beta_{t}[\text { goiter } \times I(t=\text { birthyear })]+\text { Controls }+\epsilon
$$

where $y_{i}$ is a dummy variable coded one if the individual entered the AAF and zero if they did not.

The goiter rate interacted with a set of birth year dummies provides the main coefficients of interest. The year iodized salt was introduced, 1924, is the excluded category. Iodized salt first became available in May 1924, and take-up, while rapid, was not instantaneous. Field et al. (2009) provide evidence that the first trimester of gestation is the most relevant period for the cognitive impact of iodine deficiency. Thus the vast majority of those born in 1924 would not have been treated at all. The pattern of coefficients on the interaction of goiter and birth year dummies will show how the relationship between the geologically determined level of iodine deficiency (as measured by goiter rates in WWI enlistees) and cognitive ability (as measured by the likelihood of entering the AAF) changes over time. The iodization of salt in 1924 should make these coefficients significantly larger (less negative) in the later years.

In all the regressions we include a number of additional controls. We include a full set of Defects section dummies. In some specifications we include a goiter $\mathrm{x}$ year term to control for any unobserved trends that differ between high and low goiter areas. Since the proportion of enlistees being assigned to the AAF varies dramatically over the course of the war, we include a full set of birth year dummies $\mathrm{x}$ enlistment year dummies in one specification. This will also control for any systematic relationship between birth year, enlistment year and the propensity to enter the AAF which is shared across all members of the cohort. This implicitly provides a control for enlistment age. In another specification, instead of including birth year dummies interacted with enlistment year dummies, we include birth year dummies 
and enlistment month dummies separately ${ }^{38}$. Results are consistent across specifications ${ }^{39}$. We cluster our standard errors at the Defects section level ${ }^{40}$.

\section{$7 \quad$ Results}

Figure 17 is a graphical preview of our results. We plot the probability of joining the Air Forces for each cohort of recruits, by high-goiter and low-goiter group, according to the goiter level in their section of birth. The high goiter group contains Defects sections which are at the top $25 \%$ of the distribution with a cutoff of 5.4 goiter cases per 1000 . From Figure 17 we see the jump in the probability of joining the Air Forces for the 1925 cohort coming from a high-goiter area, relative to the same cohort coming from a low-goiter area. The jump is even more pronounced for the 1926 cohort. This is reasonable, if we assume that iodized salt caught up in the market with some lag. Note that the 1927 and 1928 cohorts only enlisted after the AAF stopped receiving preferential treatment among Army commands.

A better graphical representation of our results is given by Figure 18, which plots the average residuals for each cohort - goiter group combination, after running an OLS regression of an Air Forces dummy on enlistment month dummies (for each birth year separately, so we ran 9 regressions for this graph). Figure 18 tells the same story as Figure 17, but it's more convincing, because it accounts for the effect of enlisting in any particular month over the course of the war. Figure 18 shows clearly that for the cohorts born after iodization in a previously high-goiter area, and enlisting when there was positive selection into the Air Force, there was a jump in their probability of joining the Air Force, as opposed to those

\footnotetext{
${ }^{38}$ For this specification, we only use those recruits who enlisted from July 1940 to December 1946, because there were very few men who enlisted in the period January-June 1940.

${ }^{39}$ We have also checked whether our estimates are robust to aggregating everything at the state level of birth, rather than the section of birth, and get similar results.

${ }^{40}$ We ran similar specifications with the same datasets using education as an outcome variable, but found no effect of iodization on education. We also tried using Census Data to identify an effect of iodization on education, using the goiter level at the state of birth, rather than the section of birth. We have not found any effect of iodization on education levels. While surprising, this finding is consistent with the fact that in our data we find a very weak correlation between AGCT scores and education. Specifically, the correlation between AGCT scores and graduation from high school is $14 \%$, while the correlation between AGCT scores and having one year of college or more is just $9 \%$. 
Figure 17: Probability of joining the Air Forces

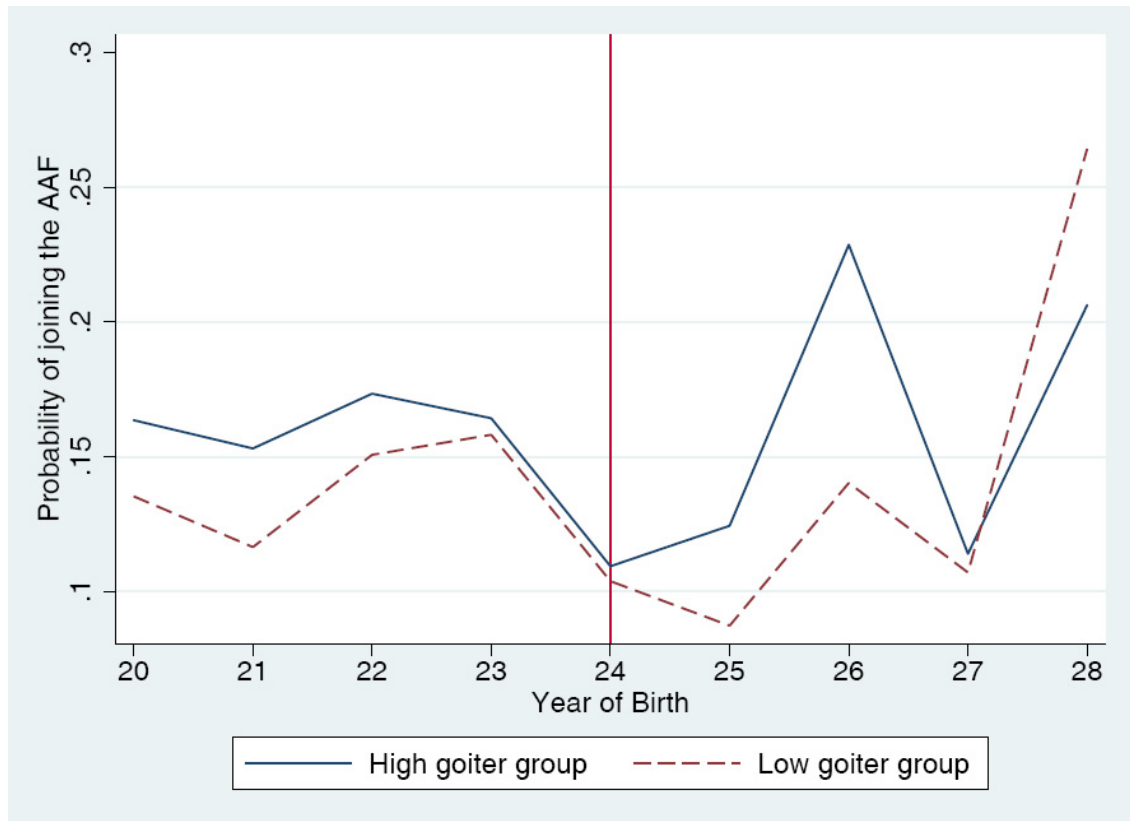

source: National Archives and Records Administration (2002) and Love and Davenport (1920)

coming from low-goiter areas. One can go as far as saying that Figure 18 also shows the negative selection into the Air Forces for the 1928 cohort, who enlisted during the final phase of the war.

\subsection{Linear Probability Model of joining the AAF}

Table 4 displays results estimated as a linear probability model using OLS. The dependent variable is a dummy indicating whether the individual entered the Army Air Forces (AAF). The main regressors are the level of goiter in the region where the recruit was born interacted with birth year dummies. The excluded year is 1924, the year that iodized salt was introduced. In the first two columns of the table we include goiter trend (defined as the section goiter rate interacted with year of birth).

There is a clear break before and after the excluded year 1924. The coefficients for 1922 and 1923 are small and insignificant. The coefficients on 1925 and 1926 are positive and 
Table 4: Air Forces dummy against initial goiter level interacted with birth year dummies

\begin{tabular}{|c|c|c|c|c|}
\hline & $\begin{array}{c}(1) \\
\text { Air Forces } \\
\text { dummy }\end{array}$ & $\begin{array}{c}(2) \\
\text { Air Forces } \\
\text { dummy }\end{array}$ & $\begin{array}{c}(3) \\
\text { Air Forces } \\
\text { dummy }\end{array}$ & $\begin{array}{c}(4) \\
\text { Air Forces } \\
\text { dummy }\end{array}$ \\
\hline goiter X birthyear20 & & & $\begin{array}{c}0.132 * \\
{[0.069]}\end{array}$ & $\begin{array}{c}0.081 \\
{[0.121]}\end{array}$ \\
\hline goiter X birthyear21 & $\begin{array}{l}0.101 * * \\
{[0.040]}\end{array}$ & $\begin{array}{l}0.146 * * * \\
{[0.045]}\end{array}$ & $\begin{array}{l}0.200 * * * \\
{[0.067]}\end{array}$ & $\begin{array}{l}0.207 * \\
{[0.106]}\end{array}$ \\
\hline goiter X birthyear22 & $\begin{array}{c}0.058 \\
{[0.067]}\end{array}$ & $\begin{array}{l}0.070 \\
{[0.067]}\end{array}$ & $\begin{array}{c}0.124 \\
{[0.079]}\end{array}$ & $\begin{array}{c}0.111 \\
{[0.102]}\end{array}$ \\
\hline goiter X birthyear23 & $\begin{array}{c}-0.057 * \\
{[0.033]}\end{array}$ & $\begin{array}{c}-0.085 * \\
{[0.048]}\end{array}$ & $\begin{array}{r}-0.024 \\
{[0.026]}\end{array}$ & $\begin{array}{c}-0.065 * \\
{[0.034]}\end{array}$ \\
\hline goiter X birthyear 25 & $\begin{array}{l}0.378 * * * \\
{[0.110]}\end{array}$ & $\begin{array}{l}0.323 * * * \\
{[0.088]}\end{array}$ & $\begin{array}{l}0.345 * * * \\
{[0.110]}\end{array}$ & $\begin{array}{l}0.303 * * * \\
{[0.084]}\end{array}$ \\
\hline goiter X birthyear26 & $\begin{array}{l}0.593 * * \\
{[0.229]}\end{array}$ & $\begin{array}{l}0.533 * * * \\
{[0.168]}\end{array}$ & $\begin{array}{l}0.527 * * \\
{[0.227]}\end{array}$ & $\begin{array}{l}0.493 * * * \\
{[0.187]}\end{array}$ \\
\hline goiter X birthyear27 & $\begin{array}{c}0.120 \\
{[0.100]}\end{array}$ & $\begin{array}{c}0.041 \\
{[0.122]}\end{array}$ & $\begin{array}{c}0.021 \\
{[0.084]}\end{array}$ & $\begin{array}{r}-0.020 \\
{[0.068]}\end{array}$ \\
\hline goiter X birthyear28 & $\begin{array}{r}-0.299 \\
{[0.190]}\end{array}$ & $\begin{array}{r}-0.363 \\
{[0.266]}\end{array}$ & $\begin{array}{c}-0.432 * * * \\
{[0.162]}\end{array}$ & $\begin{array}{c}-0.444 * * \\
{[0.183]}\end{array}$ \\
\hline goiter X year of birth & $\begin{array}{c}-0.033 * \\
{[0.017]}\end{array}$ & $\begin{array}{r}-0.020 \\
{[0.030]}\end{array}$ & & \\
\hline Constant & $\begin{array}{l}27.748 * * * \\
{[1.942]}\end{array}$ & $\begin{array}{l}40.052 * * * \\
{[4.762]}\end{array}$ & $\begin{array}{l}24.744 * * * \\
{[1.494]}\end{array}$ & $\begin{array}{l}38.211 * * * \\
{[3.865]}\end{array}$ \\
\hline $\begin{array}{l}\text { Birth year X Enlistment } \\
\text { year dummies }\end{array}$ & YES & $\mathrm{NO}$ & YES & $\mathrm{NO}$ \\
\hline Birth year dummies & $\mathrm{NO}$ & YES & $\mathrm{NO}$ & YES \\
\hline $\begin{array}{l}\text { Enlistment month } \\
\text { dummies }\end{array}$ & $\mathrm{NO}$ & YES & $\mathrm{NO}$ & YES \\
\hline Section dummies & YES & YES & YES & YES \\
\hline Observations & $2,275,622$ & $2,274,698$ & $2,275,622$ & $2,274,698$ \\
\hline R-squared & 0.127 & 0.129 & 0.127 & 0.129 \\
\hline
\end{tabular}

Notes: Robust standard errors in brackets: ${ }^{* * *} \mathrm{p}<0.01,{ }^{* *} \mathrm{p}<0.05,{ }^{*} \mathrm{p}<0.1$; Coefficients correspond to changes in percentage points. All standard errors clustered at the state-section level. Regressions (1) and (3) include all white men enlisted in the period 1940-1946. Regressions (2) and (4) include all white men enlisted in the period July 1940-December 1946. 
Table 5: Air Forces dummy against high goiter dummy interacted with birth year dummies

\begin{tabular}{|c|c|c|c|c|}
\hline & $\begin{array}{c}(1) \\
\text { Air Forces } \\
\text { dummy }\end{array}$ & $\begin{array}{c}(2) \\
\text { Air Forces } \\
\text { dummy }\end{array}$ & $\begin{array}{c}(3) \\
\text { Air Forces } \\
\text { dummy }\end{array}$ & $\begin{array}{c}(4) \\
\text { Air Forces } \\
\text { dummy }\end{array}$ \\
\hline highgoiter X birthyear20 & & & $\begin{array}{c}0.670 \\
{[1.187]}\end{array}$ & $\begin{array}{r}-0.908 \\
{[2.315]}\end{array}$ \\
\hline highgoiter X birthyear21 & $\begin{array}{l}1.991 * * * \\
{[0.761]}\end{array}$ & $\begin{array}{l}2.454 * * * \\
{[0.695]}\end{array}$ & $\begin{array}{l}2.493 * * \\
{[1.076]}\end{array}$ & $\begin{array}{c}1.772 \\
{[1.773]}\end{array}$ \\
\hline highgoiter X birthyear22 & $\begin{array}{c}1.346 \\
{[1.227]}\end{array}$ & $\begin{array}{c}1.405 \\
{[1.109]}\end{array}$ & $\begin{array}{c}1.681 \\
{[1.260]}\end{array}$ & $\begin{array}{c}0.951 \\
{[1.479]}\end{array}$ \\
\hline highgoiter X birthyear23 & $\begin{array}{r}-0.557 \\
{[0.415]}\end{array}$ & $\begin{array}{r}-0.214 \\
{[0.722]}\end{array}$ & $\begin{array}{r}-0.390 \\
{[0.291]}\end{array}$ & $\begin{array}{r}-0.441 \\
{[0.414]}\end{array}$ \\
\hline highgoiter X birthyear25 & $\begin{array}{l}4.065 * * * \\
{[1.381]}\end{array}$ & $\begin{array}{l}2.504 * * \\
{[1.055]}\end{array}$ & $\begin{array}{l}3.897 * * \\
{[1.500]}\end{array}$ & $\begin{array}{l}2.731 * * * \\
{[0.934]}\end{array}$ \\
\hline highgoiter X birthyear26 & $\begin{array}{l}8.746 * * * \\
{[2.332]}\end{array}$ & $\begin{array}{l}6.827 * * * \\
{[1.457]}\end{array}$ & $\begin{array}{l}8.411 * * * \\
{[2.618]}\end{array}$ & $\begin{array}{l}7.281 * * * \\
{[1.964]}\end{array}$ \\
\hline highgoiter X birthyear27 & $\begin{array}{c}1.854 \\
{[1.140]}\end{array}$ & $\begin{array}{r}-0.615 \\
{[2.180]}\end{array}$ & $\begin{array}{c}1.351 \\
{[0.992]}\end{array}$ & $\begin{array}{c}0.066 \\
{[0.861]}\end{array}$ \\
\hline highgoiter X birthyear28 & $\begin{array}{c}-6.017 * \\
{[3.161]}\end{array}$ & $\begin{array}{c}-8.530 * \\
{[5.016]}\end{array}$ & $\begin{array}{l}-6.687 * * * \\
{[2.490]}\end{array}$ & $\begin{array}{l}-7.621 * * \\
{[3.106]}\end{array}$ \\
\hline highgoiter X year of birth & $\begin{array}{r}-0.168 \\
{[0.297]}\end{array}$ & $\begin{array}{c}0.227 \\
{[0.579]}\end{array}$ & & \\
\hline Constant & $\begin{array}{l}26.016 * * * \\
{[2.040]}\end{array}$ & $\begin{array}{l}37.177 * * * \\
{[4.983]}\end{array}$ & $\begin{array}{l}25.039 * * * \\
{[1.278]}\end{array}$ & $\begin{array}{l}38.501 * * * \\
{[3.828]}\end{array}$ \\
\hline $\begin{array}{l}\text { Birth year X Enlistment } \\
\text { year dummies }\end{array}$ & YES & $\mathrm{NO}$ & YES & $\mathrm{NO}$ \\
\hline Birth year dummies & $\mathrm{NO}$ & YES & $\mathrm{NO}$ & YES \\
\hline $\begin{array}{l}\text { Enlistment month } \\
\text { dummies }\end{array}$ & $\mathrm{NO}$ & YES & $\mathrm{NO}$ & YES \\
\hline Section dummies & YES & YES & YES & YES \\
\hline Observations & $2,275,622$ & $2,274,698$ & $2,275,622$ & $2,274,698$ \\
\hline R-squared & 0.128 & 0.130 & 0.128 & 0.130 \\
\hline
\end{tabular}

Notes: Robust standard errors in brackets: ${ }^{* *} \mathrm{p}<0.01,{ }^{* *} \mathrm{p}<0.05,{ }^{*} \mathrm{p}<0.1$; All standard errors clustered at the state-section level. Regressions (1) and (3) include all white men enlisted in the period 1940-1946. Regressions (2) and (4) include all white men enlisted in the period July 1940-December 1946. 
Figure 18: Residual probability of joining the Air Forces

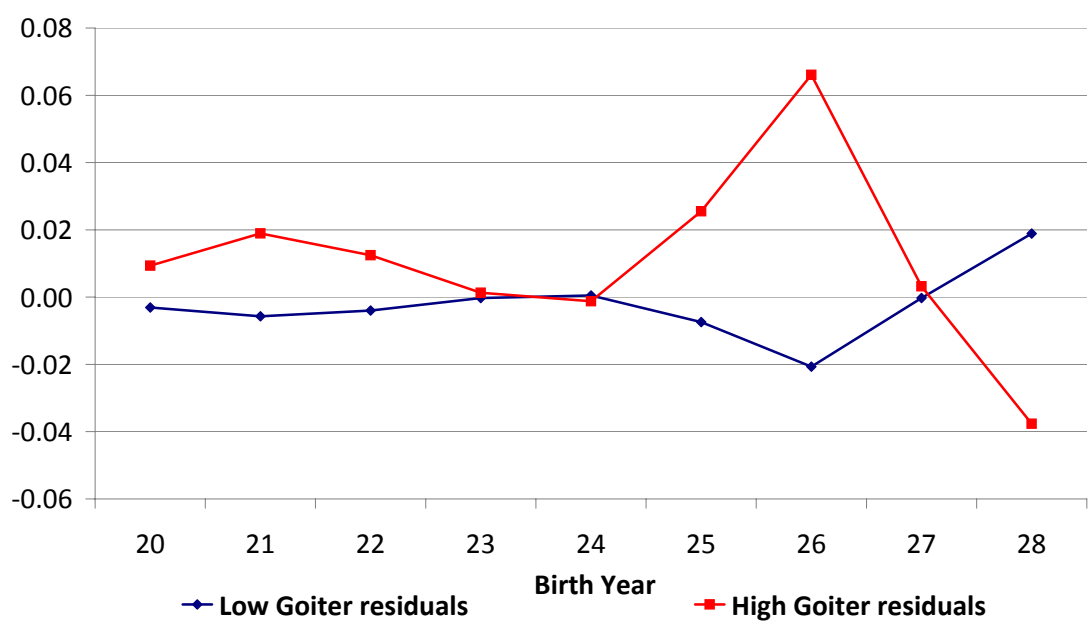

Note: Graph represents residuals from regressing AAF dummy on enlistment month dummies for each year separately, and then taking avg residual for each birth year, by goiter group

source: National Archives and Records Administration (2002) and Love and Davenport (1920)

highly significant. The fact that the coefficient rises from 1925 to 1926 is consistent with there being some lag in the diffusion of iodized salt. The later years, 1927 and 1928 are not significantly different from zero when the trend is accounted for, although 1928 is negative and significant when the trend is not included. However, as Table 3 shows, in 1927 and 1928 the selection appears to be pushing lower quality recruits toward the AAF, not higher, so we are not surprised that these years do not match the 1925 and 1926 coefficients.

The effects are large in high goiter areas. The coefficients on 1925 and 1926 are between 0.3 and 0.6 percentage points. The highest goiter areas have levels of roughly 30 per 1000 cases. Multiplying the coefficients times 30 indicates that the highest goiter areas saw a 9-18 percentage point increase in the likelihood of joining the AAF if they were born after 1924.

In Table 5 we separate the sample into high and low goiter sections. The high goiter areas are those in the top $25 \%$ of the distribution with a cutoff of 5.4 goiter cases per 1000 . The main regressors are the high goiter dummies interacted with birth year dummies. 
The results echo the earlier results. Individuals from high goiter areas see a 2.5-8.7 percentage point increase in the probability that they enter the Air Forces after the iodization of salt in 1924. Once again, the effect is bigger for 1926 than for 1925. Given that the average rate of assignment to the Air Forces was roughly 14\% for the entire sample, this represents a large effect.

\subsection{Logit results}

We also ran logit models of the probability of joining the AAF, using the same right-handside variables as in the linear probability model of the previous section. Logit results are displayed in Tables 6 and 7 .

Table 6 lists results of the interaction of goiter in the Defects section of origin and birth year dummies, whereas Table 7 lists results of the interaction of birth year dummies and a dummy variable for belonging to a high-goiter group. Regardless of the exact specification, we always see a jump in the coefficients for those cohorts born in 1925 and 1926, after salt iodization.

Table 8 lists the marginal probabilities from the logit specifications where the sample is separated in high- and low- goiter areas. The marginal probabilities are very similar to those derived with the linear probability model. Recruits born in 1925 or 1926 in previously high-goiter areas are 3-7.8 percentage points more likely to join the Air Forces.

\subsection{Falsification exercise with other diseases}

As a falsification exercise we ran regressions using data on 58 disorders other than goiter, which were also reported in Defects ${ }^{41}$. We have data on a large range of disorders and health conditions, affecting various bodily functions. Most of these disorders are quite rare, registering less than 0.5 cases per 1,000 men on average, but there are some that are more

\footnotetext{
${ }^{41}$ Specifically, we looked at all diseases that appeared on the same page as goiter in Defects.
} 
Table 6: Logit results of initial goiter level interacted with birth year dummies

\begin{tabular}{|c|c|c|c|c|}
\hline & $\begin{array}{c}(1) \\
\text { Air Forces } \\
\text { dummy }\end{array}$ & $\begin{array}{c}(2) \\
\text { Air Forces } \\
\text { dummy }\end{array}$ & $\begin{array}{c}(3) \\
\text { Air Forces } \\
\text { dummy }\end{array}$ & $\begin{array}{c}(4) \\
\text { Air Forces } \\
\text { dummy }\end{array}$ \\
\hline goiter X birthyear20 & $\begin{array}{c}0.008 \\
{[0.007]}\end{array}$ & $\begin{array}{c}0.006 \\
{[0.013]}\end{array}$ & $\begin{array}{l}0.016 * * \\
{[0.008]}\end{array}$ & $\begin{array}{c}0.010 \\
{[0.012]}\end{array}$ \\
\hline goiter X birthyear21 & $\begin{array}{l}0.017 * * \\
{[0.008]}\end{array}$ & $\begin{array}{c}0.018 \\
{[0.012]}\end{array}$ & $\begin{array}{l}0.022 * * * \\
{[0.008]}\end{array}$ & $\begin{array}{c}0.020 * \\
{[0.011]}\end{array}$ \\
\hline goiter X birthyear22 & $\begin{array}{c}0.010 \\
{[0.007]}\end{array}$ & $\begin{array}{l}0.008 \\
{[0.011]}\end{array}$ & $\begin{array}{l}0.013 * * \\
{[0.007]}\end{array}$ & $\begin{array}{c}0.010 \\
{[0.010]}\end{array}$ \\
\hline goiter X birthyear23 & $\begin{array}{r}-0.003 \\
{[0.003]}\end{array}$ & $\begin{array}{c}-0.006 * \\
{[0.003]}\end{array}$ & $\begin{array}{c}-0.001 \\
{[0.003]}\end{array}$ & $\begin{array}{c}-0.005 * \\
{[0.003]}\end{array}$ \\
\hline goiter X birthyear25 & $\begin{array}{l}0.039 * * * \\
{[0.013]}\end{array}$ & $\begin{array}{l}0.033 * * * \\
{[0.009]}\end{array}$ & $\begin{array}{l}0.037 * * * \\
{[0.013]}\end{array}$ & $\begin{array}{l}0.032 * * * \\
{[0.008]}\end{array}$ \\
\hline goiter X birthyear26 & $\begin{array}{l}0.042 * * \\
{[0.018]}\end{array}$ & $\begin{array}{l}0.036 * * * \\
{[0.013]}\end{array}$ & $\begin{array}{l}0.038 * * \\
{[0.017]}\end{array}$ & $\begin{array}{l}0.034 * * * \\
{[0.012]}\end{array}$ \\
\hline goiter X birthyear27 & $\begin{array}{c}0.011 \\
{[0.013]}\end{array}$ & $\begin{array}{c}0.001 \\
{[0.009]}\end{array}$ & $\begin{array}{c}0.005 \\
{[0.011]}\end{array}$ & $\begin{array}{r}-0.001 \\
{[0.007]}\end{array}$ \\
\hline goiter X birthyear28 & $\begin{array}{r}-0.016 \\
{[0.011]}\end{array}$ & $\begin{array}{c}-0.024 * \\
{[0.013]}\end{array}$ & $\begin{array}{c}-0.024 * * \\
{[0.010]}\end{array}$ & $\begin{array}{c}-0.028 * * \\
{[0.013]}\end{array}$ \\
\hline goiter $\mathrm{X}$ year of birth & $\begin{array}{c}-0.002 * * \\
{[0.001]}\end{array}$ & $\begin{array}{r}-0.001 \\
{[0.001]}\end{array}$ & & \\
\hline Constant & $\begin{array}{r}-0.317 \\
{[0.223]}\end{array}$ & $\begin{array}{c}0.273 \\
{[0.313]}\end{array}$ & $\begin{array}{c}-0.984 * * * \\
{[0.138]}\end{array}$ & $\begin{array}{r}-0.059 \\
{[0.185]}\end{array}$ \\
\hline $\begin{array}{l}\text { Birth year X Enlistment } \\
\text { year dummies }\end{array}$ & YES & $\mathrm{NO}$ & YES & $\mathrm{NO}$ \\
\hline Birth year dummies & $\mathrm{NO}$ & YES & $\mathrm{NO}$ & YES \\
\hline $\begin{array}{l}\text { Enlistment month } \\
\text { dummies }\end{array}$ & $\mathrm{NO}$ & YES & $\mathrm{NO}$ & YES \\
\hline Section dummies & YES & YES & YES & YES \\
\hline Observations & $2,275,622$ & $2,274,698$ & $2,275,622$ & $2,274,698$ \\
\hline Pseudo R-squared & 0.140 & 0.157 & 0.140 & 0.157 \\
\hline
\end{tabular}

Notes: Robust standard errors in brackets: ${ }^{* * *} \mathrm{p}<0.01,{ }^{* *} \mathrm{p}<0.05,{ }^{*} \mathrm{p}<0.1$; All standard errors clustered at the state-section level. Regressions (1) and (3) include all white men enlisted in the period 1940-1946. Regressions (2) and (4) include all white men enlisted in the period July 1940-December 1946. 
Table 7: Logit results of high-goiter group dummy interacted with birth year dummies

\begin{tabular}{|c|c|c|c|c|}
\hline & $\begin{array}{c}(1) \\
\text { Air Forces } \\
\text { dummy }\end{array}$ & $\begin{array}{c}(2) \\
\text { Air Forces } \\
\text { dummy }\end{array}$ & $\begin{array}{c}(3) \\
\text { Air Forces } \\
\text { dummy }\end{array}$ & $\begin{array}{c}(4) \\
\text { Air Forces } \\
\text { dummy }\end{array}$ \\
\hline highgoiter X birthyear20 & $\begin{array}{l}0.214 * * \\
{[0.096]}\end{array}$ & $\begin{array}{c}0.050 \\
{[0.186]}\end{array}$ & $\begin{array}{c}0.168 * \\
{[0.098]}\end{array}$ & $\begin{array}{r}-0.017 \\
{[0.193]}\end{array}$ \\
\hline highgoiter X birthyear21 & $\begin{array}{l}0.375 * * * \\
{[0.102]}\end{array}$ & $\begin{array}{c}0.260 * \\
{[0.155]}\end{array}$ & $\begin{array}{l}0.340 * * * \\
{[0.107]}\end{array}$ & $\begin{array}{c}0.210 \\
{[0.161]}\end{array}$ \\
\hline highgoiter X birthyear22 & $\begin{array}{l}0.250 * * * \\
{[0.095]}\end{array}$ & $\begin{array}{c}0.135 \\
{[0.130]}\end{array}$ & $\begin{array}{l}0.227 * * \\
{[0.098]}\end{array}$ & $\begin{array}{c}0.102 \\
{[0.133]}\end{array}$ \\
\hline highgoiter X birthyear23 & $\begin{array}{c}0.017 \\
{[0.033]}\end{array}$ & $\begin{array}{r}-0.021 \\
{[0.040]}\end{array}$ & $\begin{array}{c}0.005 \\
{[0.033]}\end{array}$ & $\begin{array}{r}-0.037 \\
{[0.041]}\end{array}$ \\
\hline highgoiter X birthyear25 & $\begin{array}{l}0.488 * * * \\
{[0.162]}\end{array}$ & $\begin{array}{l}0.317 * * * \\
{[0.102]}\end{array}$ & $\begin{array}{l}0.500 * * * \\
{[0.160]}\end{array}$ & $\begin{array}{l}0.334 * * * \\
{[0.101]}\end{array}$ \\
\hline highgoiter X birthyear26 & $\begin{array}{l}0.648 * * * \\
{[0.181]}\end{array}$ & $\begin{array}{l}0.503 * * * \\
{[0.121]}\end{array}$ & $\begin{array}{l}0.670 * * * \\
{[0.176]}\end{array}$ & $\begin{array}{l}0.536 * * * \\
{[0.120]}\end{array}$ \\
\hline highgoiter X birthyear27 & $\begin{array}{c}0.193 \\
{[0.124]}\end{array}$ & $\begin{array}{c}0.002 \\
{[0.088]}\end{array}$ & $\begin{array}{c}0.228 * \\
{[0.116]}\end{array}$ & $\begin{array}{c}0.052 \\
{[0.084]}\end{array}$ \\
\hline highgoiter X birthyear28 & $\begin{array}{c}-0.334 * * \\
{[0.141]}\end{array}$ & $\begin{array}{c}-0.497 * * \\
{[0.211]}\end{array}$ & $\begin{array}{c}-0.288 * * \\
{[0.145]}\end{array}$ & $\begin{array}{c}-0.430 * * \\
{[0.206]}\end{array}$ \\
\hline highgoiter X year of birth & $\begin{array}{l}0.012 * * * \\
{[0.003]}\end{array}$ & $\begin{array}{l}0.017 * * * \\
{[0.003]}\end{array}$ & & \\
\hline Constant & $\begin{array}{c}-1.285 * * * \\
{[0.062]}\end{array}$ & $\begin{array}{c}-0.415 * * \\
{[0.185]}\end{array}$ & $\begin{array}{c}-1.009 * * * \\
{[0.094]}\end{array}$ & $\begin{array}{r}-0.013 \\
{[0.177]}\end{array}$ \\
\hline $\begin{array}{l}\text { Birth year X Enlistment } \\
\text { year dummies }\end{array}$ & YES & NO & YES & $\mathrm{NO}$ \\
\hline Birth year dummies & $\mathrm{NO}$ & YES & $\mathrm{NO}$ & YES \\
\hline $\begin{array}{l}\text { Enlistment month } \\
\text { dummies }\end{array}$ & NO & YES & NO & YES \\
\hline Section dummies & YES & YES & YES & YES \\
\hline Observations & $2,275,622$ & $2,274,698$ & $2,275,622$ & $2,274,698$ \\
\hline Pseudo R-squared & 0.140 & 0.157 & 0.140 & 0.157 \\
\hline
\end{tabular}

Notes: Robust standard errors in brackets: ${ }^{* *} \mathrm{p}<0.01,{ }^{* *} \mathrm{p}<0.05,{ }^{*} \mathrm{p}<0.1$; All standard errors clustered at the state-section level. Regressions (1) and (3) include all white men enlisted in the period 1940-1946. Regressions (2) and (4) include all white men enlisted in the period July 1940-December 1946. 
Table 8: Marginal Probabilities of logit results of high-goiter group dummy interacted with birth year dummies

\begin{tabular}{ccccc}
\hline & $(1)$ & $(2)$ & $(3)$ & $(4)$ \\
variable & $\mathbf{d y} / \mathbf{d x}$ & $\mathbf{d y} / \mathbf{d x}$ & $\mathbf{d y} / \mathbf{d x}$ & $\mathbf{d y} / \mathbf{d x}$ \\
\hline highgoiter X birthyear20* & 0.021 & 0.004 & 0.016 & -0.001 \\
& {$[2.06]$} & {$[0.26]$} & {$[1.62]$} & {$[-0.09]$} \\
highgoiter X birthyear21* & 0.039 & 0.024 & 0.035 & 0.019 \\
& {$[3.21]$} & {$[1.53]$} & {$[2.81]$} & {$[1.21]$} \\
highgoiter X birthyear22* & 0.025 & 0.012 & 0.022 & 0.009 \\
& {$[2.38]$} & {$[0.99]$} & {$[2.11]$} & {$[0.73]$} \\
highgoiter X birthyear23* & 0.002 & -0.002 & 0.001 & -0.003 \\
& {$[0.51]$} & {$[-0.51]$} & {$[0.16]$} & {$[-0.92]$} \\
highgoiter X birthyear25* & 0.053 & 0.030 & 0.055 & 0.032 \\
& {$[2.54]$} & {$[2.75]$} & {$[2.63]$} & {$[2.90]$} \\
highgoiter X birthyear26* & 0.075 & 0.051 & 0.078 & 0.056 \\
& {$[2.90]$} & {$[3.48]$} & {$[3.08]$} & {$[3.69]$} \\
highgoiter X birthyear27* & 0.0189 & 0.0002 & 0.0225 & 0.0045 \\
& {$[1.46]$} & {$[0.02]$} & {$[1.80]$} & {$[0.61]$} \\
highgoiter X birthyear28* & -0.027 & -0.035 & -0.023 & -0.031 \\
& {$[-2.69]$} & {$[-2.86]$} & {$[-2.22]$} & {$[-2.46]$} \\
\hline
\end{tabular}

Notes: $\left(^{*}\right) \mathrm{dy} / \mathrm{dx}$ is for discrete change of dummy variable from 0 to $1 . \mathrm{z}$ statistic in brackets. 
Figure 19: Falsification exercise graphs

(A)

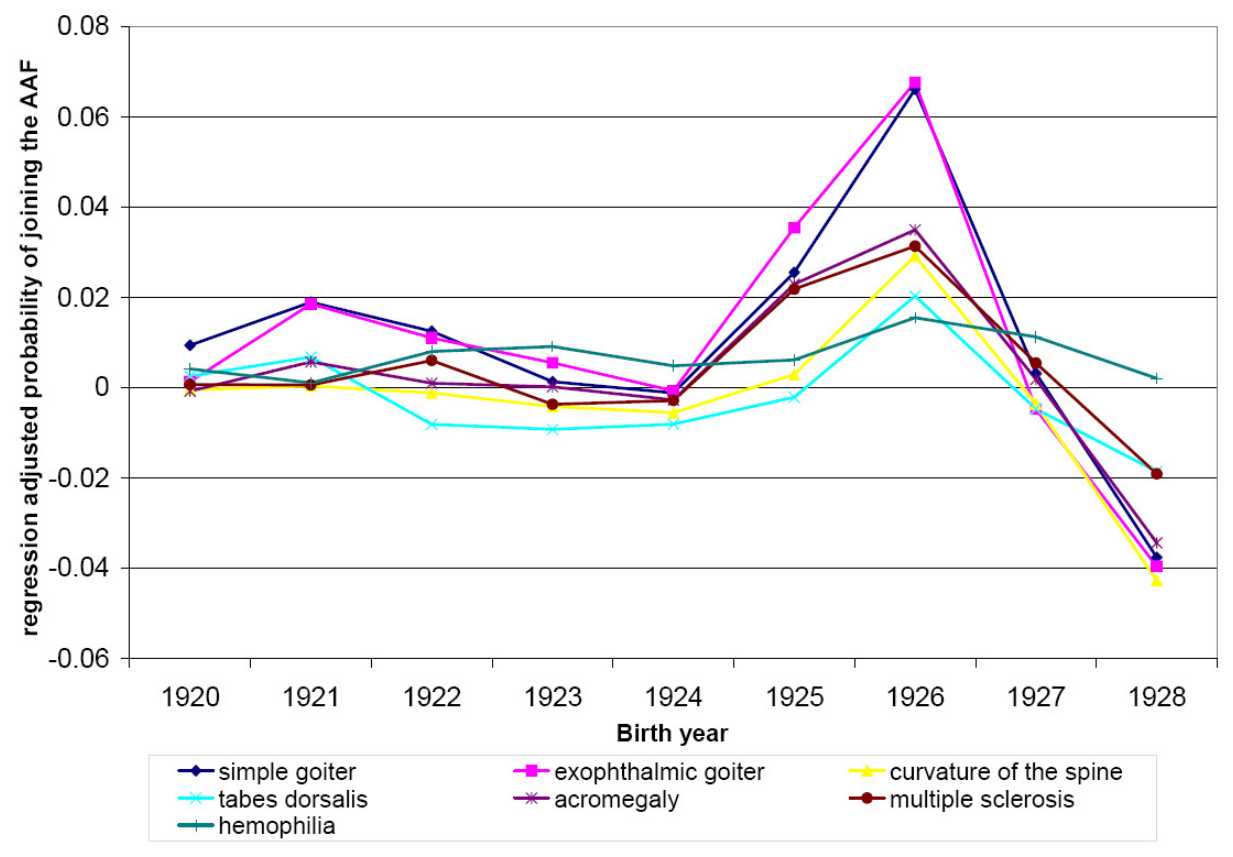

(B)

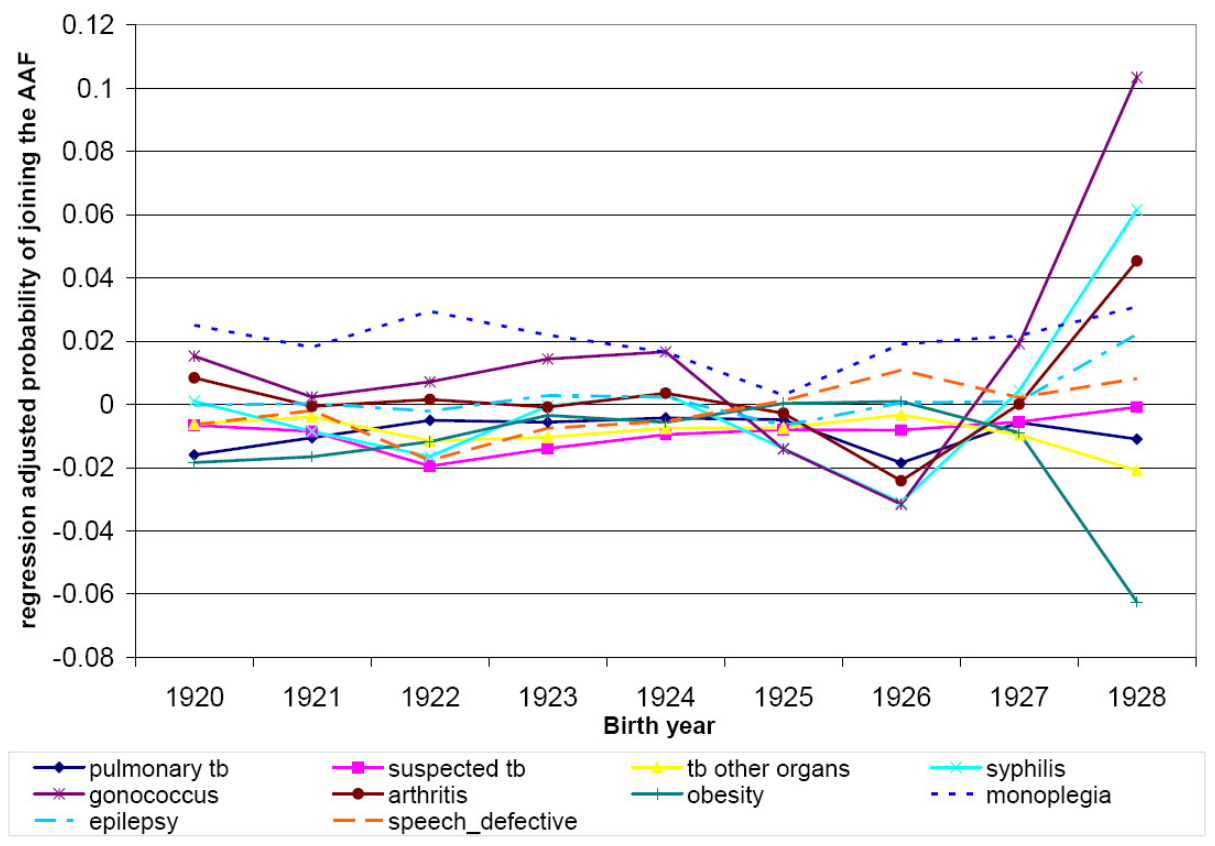

source: National Archives and Records Administration (2002) and Love and Davenport (1920) 
prevalent. For example, pulmonary tuberculosis and gonorrhea ${ }^{42}$ affected more than $10 \%$ of men recruited from certain regions of Colorado and Maryland during the WWI draft.

For each of the 58 disorders we computed the same linear probability model of joining the Air Forces as the one in column (3) of Table 4. Finding significant coefficients for cohorts born in 1925-1926, similar to those of Table 4, would cast doubt on our results from the previous regressions. Our results show, however, that the time pattern for goiter is replicated exactly (positive and significant coefficient for those born in 1925 and 1925) in only six of 58 defects: exophthalmic goiter (hyperthyroidism), acromegaly, multiple sclerosis, tabes dorsalis (syphilitic myelopathy), curvature of the spine, and hemophilia. All of these disorders, with the exception of exophthalmic goiter, are quite rare, and many sections in Defects report no cases of these defects. Exophthalmic goiter has a similar but somewhat lower prevalence than simple goiter (registering on average about 3 cases per 1,000 men). In addition, for all of these disorders there exists a link connecting them to iodine deficiency and hypothyroidism, or suggesting that iodine supplementation might have decreased their prevalence. These links are described below.

Exophthalmic goiter (hyperthyroidism) can be the result of iodine deficiency, and it is very strongly correlated with simple goiter (hypothyroidism) in our data. In addition, it has been shown to respond to iodine treatment ${ }^{43}$. Therefore the fact that the coefficients corresponding to exophthalmic goiter are similar to those of simple goiter is not surprising.

There is some evidence in the medical literature that acromegaly, a condition associated with excessive production of growth hormones, might result in stimulation of thyroid cells and thus also trigger goiters ${ }^{44}$. Prevalence of goiter and acromegaly are positively correlated in our data, though acromegaly is a rare disorder, occurring on average in fewer than 0.02 cases per 1,000. In addition, there are medical reasons why acromegaly might have been

\footnotetext{
${ }^{42}$ Recorded as gonococcus.

${ }^{43}$ See, for example, Read, Tansey and Menda (2004).

${ }^{44}$ Goiter is often found in patients with acromegaly. See, for example, Mukhtar, Wilkinson, Alexander, Appleton and Hall (1971).
} 
affected by salt iodization, which would explain the pattern we observe in the data ${ }^{45}$.

Hypothyroidism, caused by iodine deficiency and resulting in goiters, has been associated with acquired von Willebrand disease. Von Willebrand disease is a bleeding disorder similar to hemophilia, and it has been shown to respond to thyroid treatment ${ }^{46}$. In Defects, this disease is most likely grouped together with hemophilia, and it is weakly positively correlated with goiter prevalence. Given its association with hypothyroidism, it is not surprising that the hemophilia coefficients follow the pattern of the coefficients for goiter.

Curvature of spine (scoliosis) is also weakly positively correlated with goiter and may be related to iodine deficiency, because thyroid hormone plays a significant role in bone growth. In addition, an association between goiter and multiple sclerosis has also been established; a study at the state level in the United States has found that multiple sclerosis as well as other neurological disorders occur most often in recently glaciated, iodine-deficient regions ${ }^{47}$. Multiple sclerosis is positively correlated with goiter in our WWI draft data. Finally, iodine therapy is part of the treatment for tabes dorsalis (Bennett (1936)), which might explain why the coefficients for that disease follow the sample pattern as those for goiter, though we must note that tabes dorsalis is not correlated with goiter in our WWI data.

In terms of other disorders which might be related to iodine deficiency, we note that the coefficient for diseases of the ductless glands jumps for the 1925 cohort, but remains insignificant afterwards. Ductless glands are directly related to the function of the endocrine system, which is affected by the lack of iodine. In addition, cretinism and myxedema, which is a consequence of severe iodine deficiency, has the same pattern of coefficients as goiter, though the jump is not significant, possibly because of its very low prevalence and variation in the data.

Figure 19 shows regression-adjusted probabilities of joining the Air Forces for each cohort,

\footnotetext{
${ }^{45}$ Salt iodization might decrease the prevalence of acromegaly, because iodine repletion has been shown to increase the Insulin-Like Growth Factor (IGF-1) (see Zimmermann, Jooste, Mabapa, Mbhenyane, Schoeman, Biebinger, Chaouki, Bozo, Grimci and Bridson (2007)), which would result in a decrease in excessive growth hormone secretion, thus decreasing the prevalence of acromegaly.

${ }^{46}$ See Dalton, Savidge, Matthews, Dewar, Kernoff, Greaves and Preston (1987).

${ }^{47}$ Foster (1999).
} 
both for the defects that follow the same pattern as goiter (part (A)), as well as for some of the other disorders that do not $(\text { part }(B))^{48}$. Figure 19 is constructed in the same way as Figure 18, in the sense that we are controlling for enlistment month, and allowing for the effect to be different for each cohort. Because of space limitations, we only show how the residual probability changed for the high-prevalence areas (which correspond to the 75th percentile of the population-weighted distribution for each disorder).

\section{Interpretation of coefficients}

In this section we translate the results of our regressions in section 7 into a measure of the implied intelligence increases in the population following iodine supplementation. To do so, we construct a simple model of the selection in to the Army Air Forces. We write the model in terms of IQ scores, which are more conventional measure than the AGCT scores that were actually used in the selection of recruits.

Consider a pool of recruits composed of two populations. A fraction $(1-\phi)$ of recruits are from regions in which there is no iodine deficiency. Let their intelligence be represented by a random variable $I Q$ that is distributed normally with mean of 100 and standard deviation of 15. A fraction $\phi$ of recruits are from iodine deficient regions. Prior to treatment, their intelligence is given by the random variable $I Q_{d}$, distributed normally with a mean of $X$ and a standard deviation of 15 . The average level of IQ in the population would be $\overline{I Q}=$ $\phi X+(1-\phi) 100$. After treatment, the distributions are assumed to be identical.

As discussed above, a specific fraction of AAF recruits scored above the mean on the AGCT. Given this, we wish to examine how the probability of entering the AAF differs between the two population before and after treatment. Let $\psi$ be the fraction of recruits entering the AAF that had AGCT scores above the mean, and let $\theta$ be the fraction of the overall pool of recruits that entered the AAF.

\footnotetext{
${ }^{48}$ In Figure 19 (part (B)) we include those disorders which occur more regularly than 1 in 1,000 at their 75th percentile, and which have a significant regression coefficient for some cohort $\mathrm{X}$ disorder interaction term in regressions similar to the one in column (3) of Table 4.
} 
The sources that we have available do not describe the exact process by which the target percentage of above-average recruits in the AAF was achieved. Here we consider a simple and robust algorithm that would have produced this result. Suppose that initially, the AAF draws randomly from the pool of recruits until it has filled its quota for recruits below the mean. Since half the distribution is below the mean, this would fill a fraction $2(1-\psi)$ of the allotted slots. To fill the remaining available slots, the AAF would draw randomly from the pool of recruits with AGCT score above the mean.

Under such an algorithm, we can calculate the probability of someone from a low-iodine region entering the $\mathrm{AAF}$ as the sum of the initial draw from the entire distribution and the secondary draw where only the top half of the distribution is considered.

$$
\operatorname{Prob}(A A F \mid \text { iodine deficiency })=2(1-\psi) \theta+\frac{(2 \psi-1) \theta \times \operatorname{Prob}\left(I Q_{d}>\overline{I Q}\right)}{(1-\phi) \operatorname{Prob}(I Q>\overline{I Q})+\phi \operatorname{Prob}\left(I Q_{d}>\overline{I Q}\right)}
$$

Similarly, the probability of someone from a non-deficient region entering the AAF is:

$$
\operatorname{Prob}(A A F \mid \text { non-deficient })=2(1-\psi) \theta+\frac{(2 \psi-1) \theta \times \operatorname{Prob}(I Q>\overline{I Q})}{(1-\phi) \operatorname{Prob}(I Q>\overline{I Q})+\phi \operatorname{Prob}\left(I Q_{d}>\overline{I Q}\right)}
$$

The difference between these two probabilities will correspond to the regression coefficient in our specification, that is, the increase in the probability of entering the AAF resulting from iodization ${ }^{49}:(2 \psi-1) \theta \frac{\operatorname{Prob}(I Q>\overline{I Q})-\operatorname{Prob}\left(I Q_{d}>\overline{I Q}\right)}{(1-\phi) \operatorname{Prob}(I Q>\overline{I Q})+\phi \operatorname{Prob}\left(I Q_{d}>\overline{I Q}\right)}$

We apply this model to our setting as follows. First Figure 10 suggests that, on average, across all the different recruitment periods (the $75 \%$ rule period, the period with no rule, and the period with two rules), about $70 \%$ of Air Force recruits had an AGCT score above the median. Thus we set $\psi=0.70$. Second, according to our data the fraction of all recruits going to the Air Force was $14 \%$. We use this value for $\theta$. Finally, we need a measure of the fraction of recruits coming from iodine-deficient regions. In practice, there was a range of iodine deficiency as recorded in the Defects data. In tables 5, 7, and 8 we arbitrarily defined our "high goiter" dummy as corresponding to the one-quarter of sections with the highest

\footnotetext{
${ }^{49}$ There is one subtle issue, which is how the cutoff for entry into the AAF would have changed when treated cohorts from iodine-deficient regions began to enter the recruit pool. At this time, the average level of AGCT scores would have gone up, and if the test were continuously re-normed, the cutoff for entry into the AAF would have gone up as well. We do not have any information about whether this took place. In the calculations presented here, we make the assumption that the cutoff did not change.
} 
Table 9: Interpretation

\begin{tabular}{cc}
\hline$X$ (Mean IQ) & Regression Coefficient \\
\hline 100 & 0 \\
95 & .015 \\
90 & .029 \\
85 & .041 \\
80 & .052 \\
75 & .060 \\
70 & .065 \\
\hline
\end{tabular}

prevalence of goiter. Thus we use a value of $\phi=0.25$, and evaluate the coefficient from the regression that used this dummy variable.

Using these parameters, Table 9 shows the implied effect of iodization on the probability of entry into the AAF for a range of possible values of $X$, the mean level of $\mathrm{IQ}$ in the iodine-deficient regions.

The estimated coefficient on the high-goiter dummy in table 5 is in the range 2.5-8.7 percentage points. Similarly, the logit specification in Table 8 implies a marginal effect of iodization on the probability of entering the AAF in the range of 3-7.8 percentage points. Comparing these estimates to Table 9, we see that the lower range of these estimates are consistent with iodization raising IQ by 15 points (that is, $X=15$ ), which is a reasonable expectation given the work of (Bleichrodt and Born 1994). However, the higher range of estimates is larger than any reasonable estimate of the increase in IQ that would have resulted from iodization. Given the uncertainty surrounding the selection process and prior literature on iodization we do not consider the larger results plausible. In any case, our results are consistent with a substantial effect in line with the existing literature. ${ }^{50}$.

Our estimates and their interpretation are based on a sample of male recruits. However,

\footnotetext{
${ }^{50}$ As mentioned above, we do not know the algorithm that was applied in order for the AAF to hit the target number of recruits with AGCT scores above the average. An alternative to the method presented here would be for the AAF to set a minimum AGCT score such that, if it took all recruits with scores above this minimum, it would hit the target percentage above the median. For a given value of $X$ (the average IQ in iodine deficient areas), such a method would produce a larger effect of iodization on the probability of entering the AAF than the method that we consider.
} 
there is a lot of evidence suggesting that females are more prone to the development of iodine deficiency disorders than males, while Field et al. (2009) also discuss experimental evidence that, in animals, females are more likely to suffer cognitive damage in utero as a result of iodine deficiency. Both Field et al. (2009) and Politi (2010) find larger effects of iodization programs on graduation rates for females than for males. Therefore, the effect of iodization on the general population might well be larger than our estimates suggest.

\section{Conclusion}

Iodization of salt in the United States was one of the first instances of broad-based food fortification, a practice that continues in wealthy countries to this day and is spreading rapidly to the developing world. The experience of the US offers a useful natural experiment for identifying the long-term effects of an important micronutrient deficiency. Prior to iodization, there was significant geographic variation in iodine deficiency, resulting from identifiable soil and water conditions. This variation can be measured using data on the prevalence of goiter, allowing us to clearly distinguish between treatment and control groups. Iodization of salt was national in scope and implemented rapidly. The key period in which iodine deficiency affects cognitive development is a narrow window during gestation. Thus we are able to easily differentiate treated from non-treated cohorts.

We find that cognitive abilities of men born in iodine-deficient regions rose relative to those born in non-deficient regions for cohorts in utero after the advent of iodization. Our measure of cognitive ability is the probability of a man being assigned to the Army Air Forces, entry into which was partially based on performance on a standardized intelligence test. Interpreting our measure in terms of IQ, our finding is that in iodine-deficient regions, iodization raised IQ scores by roughly one standard deviation, or 15 points. Given that one-

quarter of the population lived in such regions, this implies a nationwide increase in average IQ of 3.5 points. In developed countries, average IQ rose at a rate of roughly three points 
per decade for much of the twentieth century. This is the Flynn Effect, which is thought to be largely attributable to reduced health and nutrition insults in utero and among children. Thus our results are consistent with the elimination of iodine deficiency in the United States accounting for roughly one decade's worth of the Flynn Effect. 


\section{References}

Almond, Douglas, "Is the 1918 Influenza Pandemic Over? Long-Term Effects of In Utero Influenza Exposure in the Post-1940 U.S. Population," Journal of Political Economy., August 2006, 114, 672-712.

and Janet Currie, "Killing Me Softly: The Fetal Origins Hypothesis," Journal of Economic Perspectives, 2011, 25 (3), 153-72.

Andersson, Maria, Vallikkannu Karumbunathan, and Michael B Zimmermann, "Global iodine status in 2011 and trends over the past decade," The Journal of nutrition, 2012, 142 (4), 744-750.

Behrman, Jere R. and Mark R. Rosenzweig, "Returns to birthweight," Review of Economics and Statistics, 2004, 86 (2), 586-601.

Bennett, A. E., "Fever Therapy in Tabes Dorsalis: Relief of Gastric Crises and Lightning Pains by the Use of the Kettering Hypertherm," Journal of the American Medical Association, 1936, 107 (11), $845-849$.

Bishai, David and Ritu Nalubola, "The History of Food Fortification in the United States: Its Relevance for Current Fortification Efforts in Developing Countries," Economic Development and Cultural Change, October 2002, 51 (1), 37-53.

Black, Robert E, Lindsay H Allen, Zulfiqar A Bhutta, Laura E Caulfield, Mercedes De Onis, Majid Ezzati, Colin Mathers, and Juan Rivera, "Maternal and child undernutrition: global and regional exposures and health consequences," The Lancet, 2008, 371 (9608), 243-260.

Bleakley, Hoyt, "Disease and Development: Evidence from Hookworm Eradication in the American South," Quarterly Journal of Economics, February 2007, 122 (1), 73-117. 
Bleichrodt, N and M P Born, "A meta-analysis of researh on iodine and its relationship to cognitive development," in John B. Stanbury, ed., The damaged brain of iodine deficiency, New York: Cognizant Communication, 1994, pp. 195-200.

Carpenter, Kenneth J., "David Marine and the Problem of Goiter," Journal of Nutrition, April 2005, 135, 675-680.

Connolly, R. J., "An increase in thyrotoxicosis in southern Tasmania after an increase in dietary iodine," The Medical Journal of Australia, 1971, 1 (24), 1268-1271.

Copenhagen Consensus Center, "Copenhagen consensus 2008," Fredriksberg, Denmark: Copenhagen Consensus Center, 2008.

Curtis, George M. and M. Been Fertman, "Iodine in Nutrition," in "Handbook of Nutrition," second ed., American Medical Association, 1951, chapter 6, pp. 111-135.

Dalton, R.G., G.F. Savidge, K.B. Matthews, M.S. Dewar, P.B.A. Kernoff, M. Greaves, and F.E. Preston, "Hypothyroidism as a cause of acquired Von Willebrand's Disease," The Lancet, 1987, 329 (8540), 1007 - 1009.

de Benoist, Bruno, Erin Mclean, Ines Egli, and Mary Cogswell, eds, Worldwide prevalence of anemia 1993-2005: WHO Global Database on Anemia, Geneva, Switzerland: World Health Organization, 2008.

, Maria Andersson, Ines Egli, Bahi Takkouche, and Henrietta Allen, eds, Iodine status worldwide: WHO Global Database on Iodine Deficiency, Geneva, Switzerland: World Health Organization, 2004.

Ferrie, Joseph P, Karen Rolf, and Werner Troesken, "Cognitive disparities, lead plumbing, and water chemistry: Prior exposure to water-borne lead and intelligence test scores among World War Two US Army enlistees," Economics $\mathcal{G}$ Human Biology, 2012, 10 (1), 98-111. 
Field, Erica, Omar Robles, and Maximo Torero, "Iodine deficiency and schooling attainment in Tanzania," American Economic Journal: Applied Microeconomics, October 2009, 1 (4), 140-169.

Fleischer, Michael, Richard M. Forbes, Robert C. Harriss, Lennart Krook, and Joe Kubota, "Iodine," in "The relation of selected trace elements to health and disease," Vol. 1 of Geochemistry and the Environment, Washington, D.C.: National Academy of Sciences, 1974, chapter 3, pp. 26-28.

Fost, Carolyn Ann, "The Salt Industry: A Case Study in the Evaluation of Public Policy," unpublished Ph.D. dissertation, Southern Illinois University, 1970, pp. 49-50.

Foster, Harold D., "Parkinson's Disease, Multiple Sclerosis and Amyotrophic Lateral Sclerosis: The Iodine-Dopachrome-Glutamate Hypothesis," Journal of Orthomolecular Medicine, 1999, 14 (3), 128 - 136.

Grove, Robert D. and Alice M. Hetzel, Vital statistics rates in the United States, 1940-1960, U.S. Department of health, education, and welfare, Public Health Service, National Center for Health Statistics, 1968.

Katz, Frank J., Mineral Resources of the United States 1924, Department of Commerce, Washington: US Government Printing Office, 1927.

Kelly, F.C. and W.W. Snedden, "Prevalence and Geographical Distribution of Endemic Goitre," in "Endemic Goitre" number 44. In 'WHO Monograph Series.', Geneva, Switzerland: World Health Organization, 1960, p. 27.

Kohn, Lawrence A., "Goiter, Iodine and George W. Goler: the Rochester Experiment," Bulletin of the History of Medicine, 1975, 49, 389-399. 
Koutras, Demetrios A., Josip Matovinovic, and Robert Vought, "The Ecology of Iodine," in John B. Stanbury M.D. and Basil S. Hetzel, eds., Endemic Goiter and Endemic Cretinism, John Wiley and Sons, 1980, chapter 9, pp. 185-195.

Langer, P., "History of Goitre," in "Endemic Goitre" number 44. In 'WHO Monograph Series.', Geneva, Switzerland: World Health Organization, 1960, pp. 9-25.

Love, Albert G. and Charles B. Davenport, Defects Found in Drafted Men. Statistical Information Compiled from the Draft Records Showing the Physical Condition of the Men Registered and Examined in Pursuance of the Requirements of the Selective-Service Act., Washington, D.C.: Government Printing Office, 1920.

Mannar, MG Venkatesh and Lucie Bohac, Achieving Universal Salt Iodization: Lessons Learned and Emerging Issues, Ottawa, Canada: Micronutrient Initiative, 2009.

Marine, David and O.P. Kimball, "The prevention of simple goiter in man," Journal of the American Medical Association, October 1, 1921, 77 (14), 1068-1070.

Markel, Howard, "When it rains, it pours":Endemic Goiter, Iodized Salt and David Murray Cowie, MD," American Journal of Public Health, 1987, 77 (2), 219-229.

Matovinovic, J. and V. Ramalingaswami, "Therapy and Prophylaxis of Endemic Goitre," in "Endemic Goitre" number 44. In 'WHO Monograph Series.', Geneva, Switzerland: World Health Organization, 1960, pp. 385-410.

McClendon, J. F., "Inverse relation between Iodin in Food and Drink and Goiter, Simple and Exophthalmic," Journal of the American Medical Association, May 1924, 82 (21), $1668-1672$.

McClure, Roy D., "Thyroid surgery as affected by the generalized use of iodized salt Salt in an Endemic Goitre Region - Preventive Surgery," Annals of Surgery, November 1934, $100(5), 924-932$. 
Micronutrient Initiative, Investing in the Future: A United Call to Action on Vitamin and Mineral Deficiencies: Global Report, 2009, Micronutrient Initiative, 2009.

Mukhtar, E., R. Wilkinson, L. Alexander, D. Appleton, and R. Hall, "Thyroid Function in Acromegaly," The Lancet, 1971, 298 (7719), 279 - 283.

National Archives and Records Administration, "World War II Army Enlistment Records, 1938-1946," 2002.

Palmer, Robert R., Bell I. Wiley, and William R. Keast, The Procurement and Training of Ground Combat Troops United States Army in World War II: The Army Ground Forces, Washington, D.C.: Center of Military History, United States Army, 1948.

Politi, Dimitra, "The impact of iodine deficiency eradication on schooling: evidence from the introduction of iodized salt in Switzerland," 2010.

Read, Charles H., Michael J. Tansey, and Yusuf Menda, "A 36-Year Retrospective Analysis of the Efficacy and Safety of Radioactive Iodine in Treating Young Graves' Patients," Journal of Clinical Endocrinology 83 Metabolism, 2004, 89 (9), 4229-4233.

Scrimshaw, Nevin S., "Malnutrition, Brain Development, Learning and Behavior," $\mathrm{Nu}$ trition Research, 1998, 18 (2), 351-379.

U.S. Department of Commerce, Mortality Statistics, Bureau of the Census, various years.

Watson, Tara, "Public Health Investments and the Infant Mortality Gap: Evidence from Federal Sanitation Interventions on U.S. Indian Reservations," Journal of Public Economics, September 2006, 90, 1537-1560.

World Health Organisation, "Is it true that lack of iodine really causes brain damage?," Online Q\&A, http://www.who.int/features/qa/17/en/index.html, May 2013. 
Zimmermann, Michael B., Pieter L. Jooste, Ngoako Solomon Mabapa, Xikombiso Mbhenyane, Serina Schoeman, Ralf Biebinger, Noureddine Chaouki, Maksim Bozo, Lindita Grimci, and John Bridson, "Treatment of Iodine Deficiency in School-Age Children Increases Insulin-Like Growth Factor (IGF)-I and IGF Binding Protein-3 Concentrations and Improves Somatic Growth," Journal of Clinical Endocrinology 83 Metabolism, 2007, 92 (2), 437-442. 